\title{
Cyclic evolution of phytoplankton forced by changes in tropical seasonality
}

Luc Beaufort ( $\nabla$ beaufort@cerege.fr)

Aix-Marseille Université, CNRS, IRD, CEREGE UM34

Clara Bolton

Aix-Marseille Université, CNRS, IRD, CEREGE UM34

Anta-Clarisse Sarr

Aix-Marseille Université, CNRS, IRD, CEREGE UM34

Baptiste Sucheras-Marx

Aix-Marseille Université, CNRS, IRD, CEREGE UM34

Yair Rosenthal

Rutgers University

Yannick Donnadieu

Aix-Marseille Université, CNRS, IRD, CEREGE UM34

Nicolas Barbarin

Aix-Marseille Université, CNRS, IRD, CEREGE UM34

\section{Samantha Bova}

Rutgers, State University of New Jersey https://orcid.org/0000-0002-5064-8775

Pauline Cornuault

Aix-Marseille Université, CNRS, IRD, CEREGE UM34

Yves Gally

Aix-Marseille Université, CNRS, IRD, CEREGE UM34

Emmeline Gray

Aix-Marseille Université, CNRS, IRD, CEREGE UM34

Jean-Charles Mazur

Aix-Marseille Université, CNRS, IRD, CEREGE UM34

Martin Tetard

Aix-Marseille Université, CNRS, IRD, CEREGE UM34

\section{Biological Sciences - Article}

Keywords: paleoceanography, climate cycles, global carbon cycle, phytoplankton evolution, tropical seasonality

Posted Date: November 9th, 2020 
DOI: https://doi.org/10.21203/rs.3.rs-100744/v1

License: (c) (1) This work is licensed under a Creative Commons Attribution 4.0 International License. Read Full License

Version of Record: A version of this preprint was published at Nature on December 1st, 2021. See the published version at https://doi.org/10.1038/s41586-021-04195-7. 
Cyclic evolution of phytoplankton forced by changes in tropical seasonality

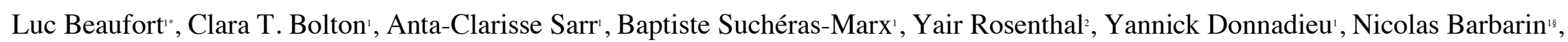

The effect of global climate cycles driven by Earth's orbital variations on evolution is poorly understood because of difficulties achieving sufficiently-resolved records of past evolution. The fossil remains of coccolithophores, a key calcifying phytoplankton group, enable an exceptional assessment of the impact of cyclic orbital-scale climate change on evolution because of their abundance in marine sediments, and because coccolithophores demonstrate extreme morphological plasticity in response to the changing environment ${ }^{12}$. Recently,

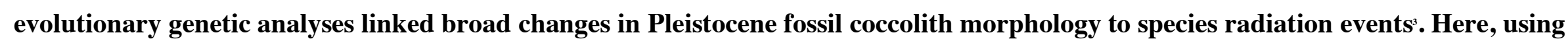
high-resolution coccolith data, we show that during the last 2.8 million years coccolithophore evolution was forced by Earth's orbital eccentricity with rhythms of $\sim 100,000$ years and 405,000 years - a distinct spectral signature to that of coeval global climate cycles ${ }^{4}$ Simulations with an Earth System Model ${ }^{\circledR}$ including the marine carbon cycle ${ }^{\varsigma}$ demonstrate that eccentricity directly impacts the diversity of ecological niches occurring over the annual cycle in the tropical ocean. Reduced seasonality favours species with mid-size coccoliths that bloom year-round, increasing coccolith carbonate export and burial. We posit that eccentricity pacing of phytoplankton evolution contributed to the strong 405,000-year pacing seen in records of the global carbon cycle.

Coccolithophores are important producers of $\mathrm{CaCO}_{3}$ in the ocean and their fossil remains (calcite platelets called coccoliths) first appeared in sediments during the late Triassic ( 210 million years ago, Ma). Coccolithophores rose to dominance in the open ocean during the early Cretaceous $^{7}$ and thereafter become a key biological modulator of the global carbon cycle, via both photosynthesis and calcification ${ }^{8}$. In the dominant Noëlaerhabdaceae family (including the cosmopolitan genera Emiliania, Gephyrocapsa and Reticulofenestra), species are defined by the morphological characteristics of their coccoliths, with size being a key criterion'. For Gephyrocapsa and Emiliania, phylogenies reconstructed from gene sequence data indicate that morphology-based definitions correspond to biological species ${ }^{3,10}$. Yet, within a given Noëlaerhabdaceae population, interspecific and intraspecific changes in coccolith length and mass (the latter encoding degree of calcification as well as size) occur in response to environmental parameters such as carbonate chemistry' and temperature ${ }^{2}$. Existing studies of coccolithophore evolution have focused on geological-timescale changes in species richness and turnover ${ }^{11}$, coccolith carbonate accumulation ${ }^{7,12}$, or calcification potentially driven by carbon cycle changes ${ }^{13}$. However, to date a lack of records that are both long-term and high-resolution has precluded an understanding of the impact of orbital cycles (on timescales of tens to hundreds of thousands of years) on coccolithophore evolution and carbonate production. 
Here, we quantify the history of tropical Noëlaerhabdaceae evolution throughout the Pleistocene at high resolution $(\sim 2$ thousand years, kyr), using coccoliths preserved in nine well-dated sedimentary sections from the tropical Indian and Pacific Oceans (Fig. 1; Extended Data Table 1;

Methods). We use artificial intelligence microscopy to create an unprecedented biometric database of over 7 million coccoliths from $>8000$ samples (see Methods). The remarkable similarity of morphometric patterns observed at each site has led us to build evolutionary histograms of coccolith size and mass. To create these, we binned data into 30-kyr intervals to erase any precession-band variability driven by ecology ${ }^{14}$ and to increase the statistical robustness of each point, now composed of measurements of tens of thousands of individual coccoliths (Fig. $2 \mathrm{a}$; Methods). Evolutionary histograms for size and mass show identical trends and variability, we therefore only discuss the size record. The data show multiple phases of contraction alternating with phases of dilation characterised by bimodal or broader morphological distributions (Fig. 2a). Patches of high abundance of a particular morphotype correspond in many cases to described acmes of Noëlaerhabdaceae species ${ }^{15-17}$. The most recent dilation phase that started around 450 thousand years ago $(\mathrm{ka})$ has been attributed to a radiation event and the emergence of new Gephyrocapsa species, based on a consensus phylogeny reconstructed from genome sequence data and its temporal correlation to low-resolution coccolith morphometric data ${ }^{3}$. Over the entire record, average coccolith size shows an increasing trend that corresponds to a gradual shift in dominance from smaller to larger coccoliths during the Pleistocene (Fig. 2b). On orbital time scales, coccolith size and global ice volume and temperature cycles as represented by the $\delta{ }^{18} \mathrm{O}$ of benthic foraminifers ${ }^{18}$ show very different temporal evolution (Fig. $2 \mathrm{c}$ ). Instead the size contraction and dilation alternations follow a regular cycle that is highly coherent (>99.9\%) with the orbital eccentricity periods of 405 kyr (e405) and of 124 and 95 (e100) ${ }^{19}$ (Extended Data Figure 1a), with contractions (dilations) occurring at low (high) eccentricity with a slight time lag (Fig. 2b).

The average size or mass of coccoliths in a Noëlaerhabdaceae population may vary over time because of macro- and/or micro-evolution, or because ecological changes modulate the relative abundances of species in different size ranges. To remove the effect of relative abundance changes, we create a novel Morphological Divergence Index, MDI, that represents the difference in average coccolith mass between two size classes, larger and smaller than 3 $\mu \mathrm{m}$ (Extended Data Figure 2; Methods). MDI records from individual sites are highly intercorrelated (Extended Data Figure 3) and all show significant e405 and e100 periods (Extended Data Figure 1), despite coming from distinct oceanographic biomes ${ }^{20}$ and climatic regimes (e.g. Warm Pool, monsoon-dominated; see Extended Data Table 1). We therefore produce a composite MDI stack, preserving the high resolution of each dataset (Fig. 3c; Methods). Evolutionary cross-spectral analysis indicates that the stack has highly significant (>90\%) coherency with the frequencies of Earth's eccentricity since $2.8 \mathrm{Ma}$ (Fig. 3b, b'). This pattern cannot be the result of differential dissolution on coccolith morphology, because MDI values are similar regardless of core depths, and because in contrast to MDI, Pleistocene deep-sea $\mathrm{CaCO}_{3}$ dissolution generally follows a glacial-interglacial (G-IG) pattern ${ }^{21}$. The MDI stack, interpreted as primarily reflecting evolutionary changes in morphology, shows strong 405-kyr pacing throughout the Pleistocene, irrespective of G-IG background state. While eccentricity forcing on coccolithophore productivity has previously been suggested ${ }^{2223}$, our new high-resolution multi-million-year dataset reveals that eccentricity cycles imprinted the evolution of the Noëlaerhabdaceae. Such cyclicity may have had important consequences for the oceanic carbon cycle on multiple time scales via coccolith carbonate production and burial in sediments ${ }^{1224}$. Coccolithophores are known to produce high amounts of calcite during blooms ${ }^{2225}$, and sediments are often dominated by few species, for example Emiliania huxleyi (0-90 ka) ${ }^{15}$ and Gephyrocapsa caribbeanica $(280-570 \mathrm{ka})^{16}$ in the late Pleistocene. We estimate the $\mathrm{CaCO}_{3}$ mass accumulation rate $(\mathrm{MAR})$ of Noëlaerhabdaceae coccoliths in our cores and produce a stacked $\mathrm{CaCO}_{3} \mathrm{MAR}$ record (Fig. 3e, Methods). This reveals that higher MARs correspond to lower MDI values when mid-size bloom species, which contribute the most to coccolith carbonate export, dominate. The dominance of these bloom species coupled with high coccolithophore production and accumulation in sediments during eccentricity minima is also recorded in the extra-tropics ${ }^{22}$, attesting to the global significance of these observations. In our records, the two main components, production 
of coccoliths and individual mass, often have opposing effects on MAR since medium-size and low-mass species, such as $E$. huxleyi and $G$. carribeanica, are the most productive (Extended Data Figure 4). In addition, local ecological conditions affecting productivity and export, and potentially water depth affecting coccolith preservation, likely also influence MAR, although it is not possible to quantify the relative effects of these factors. Nevertheless, the composite MAR record shows strong eccentricity periodicities that are significantly coherent with MDI throughout the Pleistocene (Fig. 3d, d'), demonstrating a strong imprint of coccolithophore evolution on carbonate production and burial.

\section{MDI as a recorder of seasonality}

We hypothesise that our new coccolith index reflects variations in the amplitude of tropical seasonality. In low latitudes, seasonal contrast is related to the eccentricity of Earth's orbit, (1) directly because the ellipticity of the orbit determines the distance between the Sun and the Earth during each season, affecting radiation intensity, and (2) indirectly because eccentricity modulates the effect of precession on seasonal insolation contrast. Seasonal contrast is greater during periods of high eccentricity. To our knowledge, the eccentricity-paced rhythm of surface-ocean seasonality that dominates MDI has not been documented previously because most proxies record integrated annual average conditions or a specific season. The seasonal succession of coccolithophore species, a characteristic of phytoplankton ecology, is indicative of their adaptation to the different ecological niches created by seasons ${ }^{26}$. Those seasonal niches are more diverse in a climate with stronger seasonality ${ }^{20}$. In the modern ocean, the highest phytoplankton diversity is found in the tropical band, a pattern probably related to high temperatures and temporal stability, whereas the seasonal species turnover is highest at mid-latitudes because of a strong seasonal contrast ${ }^{2}$. Annual records of Net Primary Production (NPP) are good descriptors of the range of oceanographic niches and biomes ${ }^{20}$. To demonstrate the effect of orbital configuration on NPP and therefore niche availability, we simulated monthly oceanic NPP using the fully-coupled IPSL-CM5A-2 model ${ }^{\circ}$, which includes the ocean biogeochemistry model PISCES-v2 $2^{\text {s }}$, for seven early Pleistocene time intervals chosen to cover a large eccentricity spectrum with different precession conditions but with similar ice volume and obliquity (lines in Fig. 2; Extended Data Table 2). The results of these simulations for the tropical eastern Indian and western Pacific Oceans show that the seasonal range of NPP increases with eccentricity, a trend that parallels the eccentricity sorted values of MDI (Fig. 4).

In the simulations, the increase in the amplitude of the NPP seasonal cycle (Fig 1; Extended Data Figure 5b-e) is primarily driven by higher productivity during boreal summer, especially in the eastern Indian ocean. This increase is forced by modification of atmosphere-ocean dynamics in response to variations in the amplitude and seasonality of insolation forcing that is amplified at extreme eccentricity values (Extended Data Figure 5g-j and 6a-c). During high eccentricity periods at precession minima (maxima), increasing (decreasing) boreal summer insolation (Extended Data Figure 6b, c) is responsible for increasing (decreasing) sea-level pressure over continental Asia (Extended Data Figure 6e-h). Induced modifications of sea-level pressure gradients over the tropical Indian and Pacific Oceans in turn translate into changes in the lowlevel wind circulation over the Indo-Pacific Warm Pool, IPWP, (Extended Data Figure 5g-j). Anomalous easterlies at precession minima (westerlies at precession maxima) in the equatorial region generate anomalous upwelling along the equator (SW of India) that are responsible for the increasing nutrient content at the surface triggering large enhancement of productivity (Extended Data Figure 7a-c). NPP is, in addition, amplified by modifications of the hydrological cycle that create more favourable conditions related to changes in salinity, water temperature and/or amount of solar radiation at the surface. At maximum precession and eccentricity, for example, higher sub-surface salinity $(+0.5$ to 1.6 psu) and lower temperatures $\left(-1.2\right.$ to $-2^{\circ} \mathrm{C}$ ) in the western Bay of Bengal relative to in other simulations (Extended Data Figure 7c) reduce stratification of the upper-water column, which favours vertical mixing and contributes to enhanced productivity. Overall, those localized increases in the amplitude of the seasonal cycle lead to a less homogeneous upper ocean in the IPWP region at high eccentricity (Fig. 1 and Extended Data Figure 5a-c). We propose that during high eccentricity times, the higher seasonal range of NPP in our model simulations is 
indicative of more diverse ecological niches that coccolithophores can adapt to. A greater diversity of ecological niches when seasonality is high ${ }^{20}$ leads to a larger range of morphotypes because Noëlaerhabdaceae adaptation is characterised by the adjustment of coccolith size and degree of calcification (therefore mass) to thrive in the new environments's

\section{Eccentricity lags, species origination, and dominance}

The MDI reflects periods of dominance of a particular species or morphotype, rather than species origination events, and is clearly modulated by eccentricity. In stark contrast to most Pleistocene climate proxy records (e.g. $\left.{ }^{1.18}\right)$, precession and obliquity cycles are absent from the highresolution MDI records (Extended Data Figure 3), suggesting that evolutionary processes smooth the records. Significant lags exist between eccentricity forcing and coccolith morphology (Fig. 2b), which we hypothesize result from the time taken for favourable conditions to reoccur that allow a species to rise to dominance following its first emergence. For example, E. huxleyi first appeared at $290 \mathrm{ka}$, but did not become dominant until $90 \mathrm{ka}^{15}$. Yet speciation events spread rapidly throughout the oceans ${ }^{15,17}$, a phenomenon reflected in the small genetic diversity amongst the global Noëlaerhabdaceae population ${ }^{10}$. This time lag could result from interspecific competition. When E. huxleyi originated, Gephyrocapsa oceanica and Gephyrocapsa ericsonii already dominated coccolithophore assemblages, and the time required for $E$. huxleyi to become widespread while favourable conditions persisted was not sufficient for it to become dominant. It was not until two e100 cycles later, under similar eccentricity conditions, that $E$. huxleyi gained a competitive advantage and rose to dominance. The delay between species appearance and dominance is thus intrinsic in the MDI record, acting as a low pass-filter with a cut-off frequency of 1/200 kyr-1 (Fig. 2b, Extended Data Figure 8). For other species, the lag might have been one or two e100 cycle, providing an explanation for the non-stationary nature of the phase lag between e100 and MDI.

\section{Long-eccentricity forcing, coccolithophores, and the global carbon cycle}

The persistence of the long eccentricity cycle e 405 in Cenozoic and Mesozoic records of the ocean carbon cycle (e.g., weight percent $\mathrm{CaCO}_{3}$ and foraminiferal $\delta{ }^{13} \mathrm{Css0}$, independent of G-IG climate state, testifies to the importance of biogeochemical processes operating at this timescale throughout Earth's history. In the Pleistocene, Mediterranean surface $\delta^{13} \mathrm{C}$ records record e 405 cycles more faithfully than deep open-ocean sites, suggesting a low-latitude climatic origin of this signal ${ }^{13}$. Similar to our coccolith records, a significant phase lag between $\delta{ }^{13} \mathrm{C}$ and eccentricity is observed in the e 405 band, which has been explained by the long residence time of carbon in the oceans and resultant transfer of energy from precession into eccentricity bands via a non-linear process $^{2}$. Previous studies spanning up to $\sim 1$ Myr have linked coccolithophore production to eccentricity forcing ${ }^{142}$. However, the hypothesis proposed by Rickaby et al..$^{22}$ that eccentricity-driven changes in growing season length may be responsible for the $\sim 400$-kyr cycle in coccolithophore production cannot adequately explain changes reconstructed at our low latitude sites. Instead, our data and model results lead us to the alternative hypothesis that changes in seasonality caused by the eccentricity of the Earth's orbit paced tropical Noëlaerhabdaceae production and evolution throughout the Pleistocene. Although these changes clearly impact carbonate accumulation patterns (Fig. 3), coccolithophore productivity alone cannot be responsible for the expression of long eccentricity cycles in climate records. Other phytoplankton groups, some with little or no fossil record, must also have been influenced by variations in tropical seasonality on these timescales. In this case, the impact of changes in the ratio of exported organic carbon production to carbonate mineral production, known as the rain ratio", may have been strong enough to modulate the carbon cycle. Our data, showing cyclic evolution of calcifying phytoplankton on eccentricity timescales in response to seasonality, provide a new perspective in support of the hypothesis of Pälike et al.2s that biosphere productivity must have responded directly to changes in solar insolation in order to explain the strong e405 signature in carbon cycle records. 
Beaufort, L. et al. Sensitivity of coccolithophores to carbonate chemistry and ocean acidification. Nature 476, 80-84, doi: 10.1038/nature10295 (2011).

Henderiks, J. \& Bollmann, J. The Gephyrocapsa sea surface palaeothermometer put to the test: comparison with alkenone and foraminifera proxies off NW Africa. Mar. Micropaleontol. 50, 161-184, doi: 10.1016/S0377-8398(03)00070-7 (2004). Bendif, E. M. et al. Repeated species radiations in the recent evolution of the key marine phytoplankton lineage Gephyrocapsa. Nat. Commun. 10, 4234, doi:10.1038/s41467-019-12169-7 (2019). Ruddiman, W. F. \& Raymo, M. E. in The past three million years : Evolution of climatic variability in the North Atlantic Region (eds N.J. Shackleton, R.G. West, \& D.Q Bowen) (University Press, 1988). Sepulchre, P. et al. IPSL-CM5A2 - an Earth system model designed for multi-millennial climate simulations. Geosci. Model Dev. 13, 3011-3053, doi:10.5194/gmd-13-3011-2020 (2020). Aumont, O., Éthé, C., Tagliabue, A., Bopp, L. \& Gehlen, M. PISCES-v2: An ocean biogeochemical model for carbon and ecosystem studies. Geosci. Model Dev. 8, 2465-2513, doi: 10.5194/gmd-8-2465-2015 (2015). Suchéras-Marx, B. et al. The colonization of the oceans by calcifying pelagic algae. Biogeosciences 16, 2501-2510, doi: 10.5194/bg-162501-2019 (2019)

Ridgwell, A. \& Zeebe, R. E. The role of the global carbonate cycle in the regulation and evolution of the Earth system. Earth Planet. Sc. Lett. 234, 299-315, doi: 10.1016/j.eps1.2005.03.006 (2005). Perch-Nielsen, K. in Plankton Stratigraphy Vol. 1 (eds H.M. Bolli, J.B. Saunders, \& K. Perch-Nielsen) Ch. Cenozoic calcareous nannofossils, 427-458 (Cambridge University Press, 1985).

Filatov, D. A. Extreme Lewontin's paradox in ubiquitous marine phytoplankton species. Mol. Biol. Evol. 36, 4-14, doi:10.1093/molbev/msy195 (2019). Bown, P. R. Calcareous nannoplankton evolution: a tale of two oceans. Micropaleontol. 51, 299-308, doi: 10.2113/gsmicropal.51.4.299 (2005).

Si, W. \& Rosenthal, Y. Reduced continental weathering and marine calcification linked to late Neogene decline in atmospheric $\mathrm{CO}_{2}$. Nat. Geosci. 12, 833-838, doi:10.1038/s41561-019-0450-3 (2019).

Bolton, C. T. et al. Decrease in coccolithophore calcification and $\mathrm{CO}_{2}$ since the middle Miocene. Nat. Commun. 7, 1-13 (2016).

Beaufort, L. et al. Insolation cycles as a major control of equatorial Indian ocean primary production. Science 278, 1451-1454, doi: 10.1126/science.278.5342.1451 (1997).

Thierstein, H. R., Geitzenauer, K. R., Molfino B. \& Shackleton, N. J. Global synchroneity of late Quaternary coccolith datum levels: validation by oxygen isotopes. Geology 5, 400-404, doi: 10.1130/0091-7613(1977)5<400:GSOLQC>2.0.CO;2 (1977). Bollmann, J., Baumann, K. H. \& Thierstein, H. R. Global dominance of Gephyrocapsa coccoliths in the Late Pleistocene: Selective dissolution, evolution, or global environmental change? Paleoceanography 13, 517-529, doi:10.1029/98PA00610 (1998). Raffi, I. et al. A review of calcareous nannofossil astrobiochronology encompassing the past 25 million years. Quaternary Sci. Rev. 25, 3113-3137, doi:https://doi.org/10.1016/j.quascirev.2006.07.007 (2006).

Lisiecki, L. E. \& Raymo, M. E. A Pliocene-Pleistocene stack of 57 globally distributed benthic $\delta^{18} \mathrm{O}$ records. Paleoceanography $\mathbf{2 0}$, doi:10.1029/2004PA001071 (2005).

Laskar, J. et al. A long-term numerical solution for the insolation quantities of the Earth. Astron. Astrophys. 428, 261-285, doi:10.1051/0004-6361:20041335 (2004).

Longhurst, A. Ecological Geography of the Sea. Vol. 1 (Academic Press, 1998). 
Sexton, P. F. \& Barker, S. Onset of 'Pacific-style' deep-sea sedimentary carbonate cycles at the mid-Pleistocene transition. Earth Planet. Sc. Lett. 321-322, 81-94, doi:https://doi.org/10.1016/j.epsl.2011.12.043 (2012).

Rickaby, R. E. M. et al. Coccolith chemistry reveals secular variations in the global ocean carbon cycle? Earth Planet. Sc. Lett. 253, 8395, 10.1016/j.eps1.2006.10.016 (2007). Wang, P., Tian, J. \& Lourens, L. J. Obscuring of long eccentricity cyclicity in Pleistocene oceanic carbon isotope records. Earth Planet. Sc. Lett. 290, 319-330, doi:https://doi.org/10.1016/j.eps1.2009.12.028 (2010). Suchéras-Marx, B. \& Henderiks, J. Downsizing the pelagic carbonate factory: Impacts of calcareous nannoplankton evolution on carbonate burial over the past 17 million years. Global Planet. Change 123, 97-109, doi: 10.1016/j.gloplacha.2014.10.015 (2014). Holligan, P. M. et al. A biogeochemical study of the coccolithophore, Emiliania huxleyi, in the North Atlantic. Global Biogeochem. Cy. 7, 879-900, doi: 10.1029/93GB01731 (1993). Okada, H. \& McIntyre, A. Seasonal distribution of modern Coccolithophores in the western North Atlantic Ocean. Mar. Biol. 54, 319328, doi: 10.1007/BF00395438 (1979). Righetti, D., Vogt, M., Gruber, N., Psomas, A. \& Zimmermann, N. E. Global pattern of phytoplankton diversity driven by temperature and environmental variability. Sci. $A d v$. 5, eaau6253, doi:10.1126/sciadv.aau6253 (2019). Pälike, H. et al. The Heartbeat of the Oligocene Climate System. Science 314, 1894-1898, doi:10.1126/science.1133822 (2006). Herbert, T. D. A long marine history of carbon cycle modulation by orbital-climatic changes. P. Natl Acad. Sci. USA 94, 8362-8369, doi: 10.1073/pnas.94.16.8362 (1997). Kocken, I. J., Cramwinckel, M. J., Zeebe, R., Middelburg, J. \& Sluijs, A. The 405 kyr and 2.4 Myr eccentricity components in Cenozoic carbon isotope records. Clim. Past 15, 91-104, doi: 10.5194/cp-15-91-2019 (2019). Archer, D. \& Maier-Reimer, E. Effect of deep-sea sedimentary calcite preservation on atmospheric $\mathrm{CO}_{2}$ concentration. Nature 367, 260263, doi: 10.1038/367260a0 (1994). 


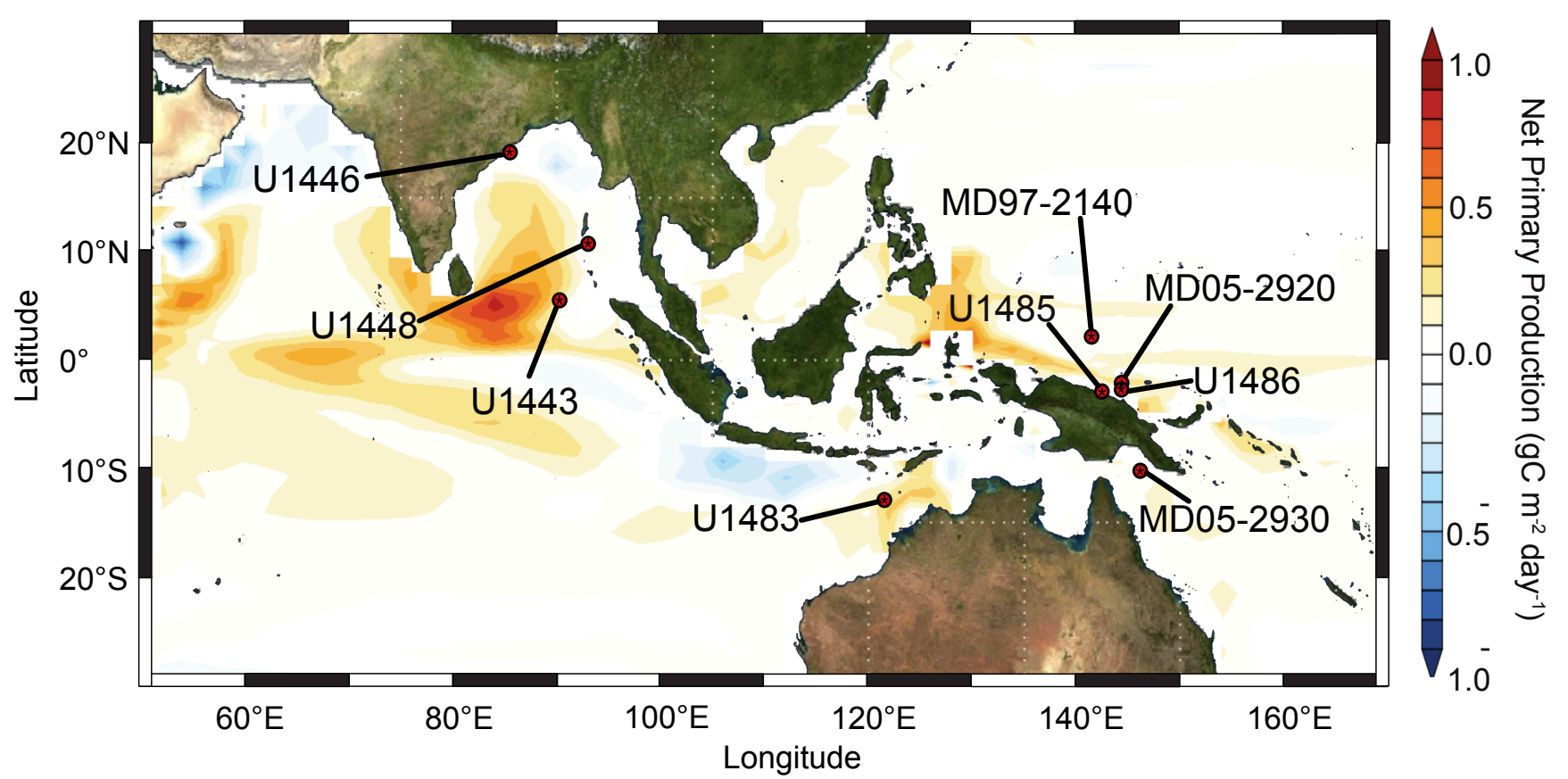

Figure 1: Core site locations and eccentricity-driven changes in seasonality of primary production in the tropical Indo-Pacific. Colour 


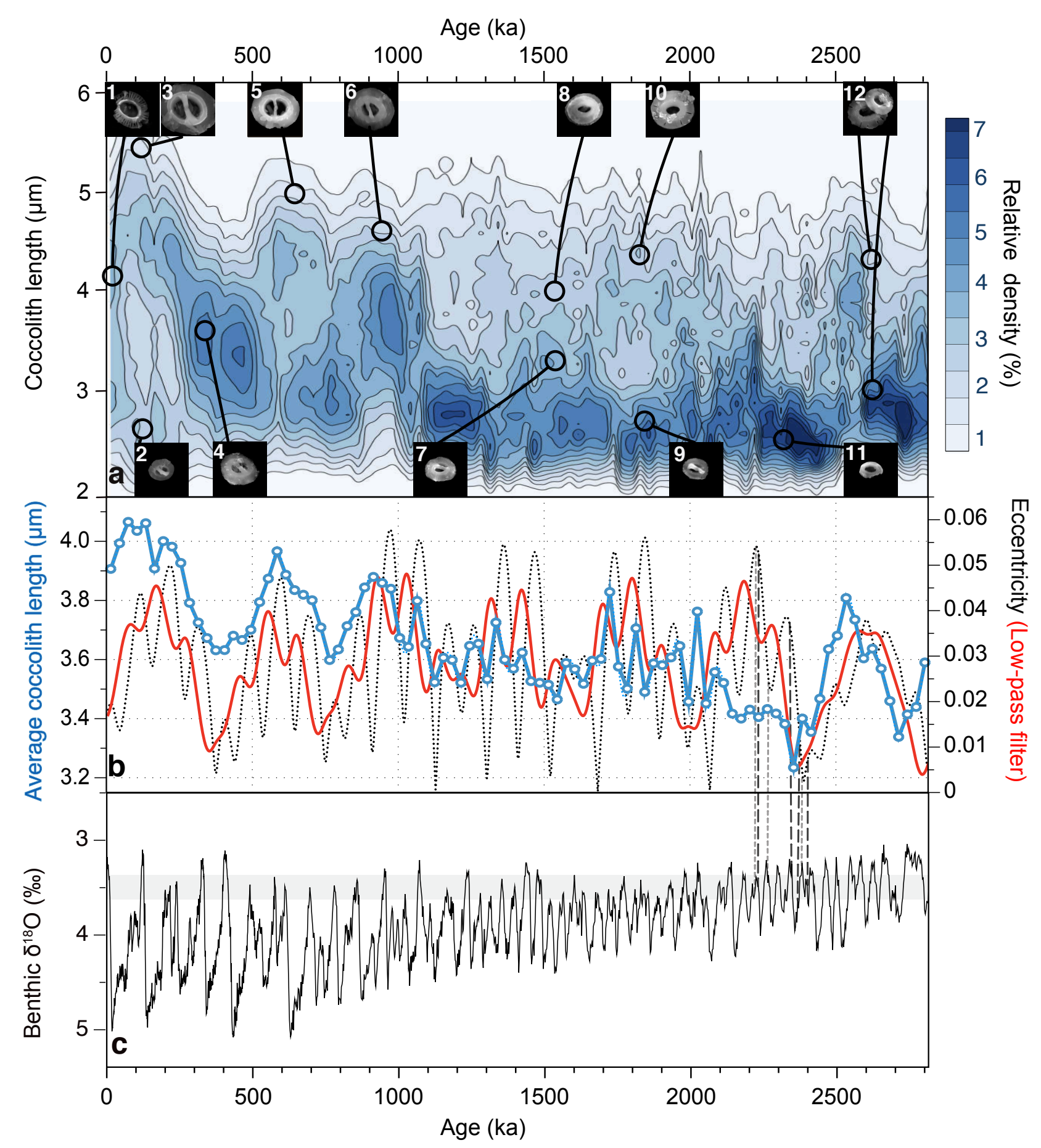

Figure 2: Coccolith size variability over the last 2.8 million years. a: Evolutionary histogram of coccolith length. Samples in each core were grouped into $30 \mathrm{kyr}$ bins, standardised (\%) and merged into a single stack (see Methods). Length bins are $0.1 \mu \mathrm{m}$. Scanning electron microscope images represent typical Noëlaerhabdaceae morphologies. 1: Emiliania huxleyi, 2: Gephyrocapsa ericsonii, 3: Gephyrocapsa oceanica, 4: Gephyrocapsa caribbeanica, 5-6: Gephyrocapsa omega, 7-8: mid-size Gephyrocapsa, 9: small Gephyrocapsa, 10: Pseudoemiliania ovata, 11: Reticulofenestra minuta, 12: left: P. ovata, right: Reticulofenestra minutula. b: Average length (blue) of coccoliths in the multi-site stack, plotted with Earth's eccentricity ${ }^{19}$ (dotted black line) and low-pass filtered eccentricity with an angular frequency of $0.021 \mathrm{kyr}^{-1}(\mathrm{red})$ and average coccolith length detrended (blue). c: LR04 benthic foraminiferal $\delta{ }^{18} \mathrm{O}$ stack $^{18}$. Vertical dashed lines between panels b and c show orbital configurations used in model simulations (black long dash = Pmin, grey short dash = Pmax; see Methods). Grey band in $\mathrm{c}$ illustrates the small range of benthic $\delta$ O $\mathrm{O}$ between simulations. 


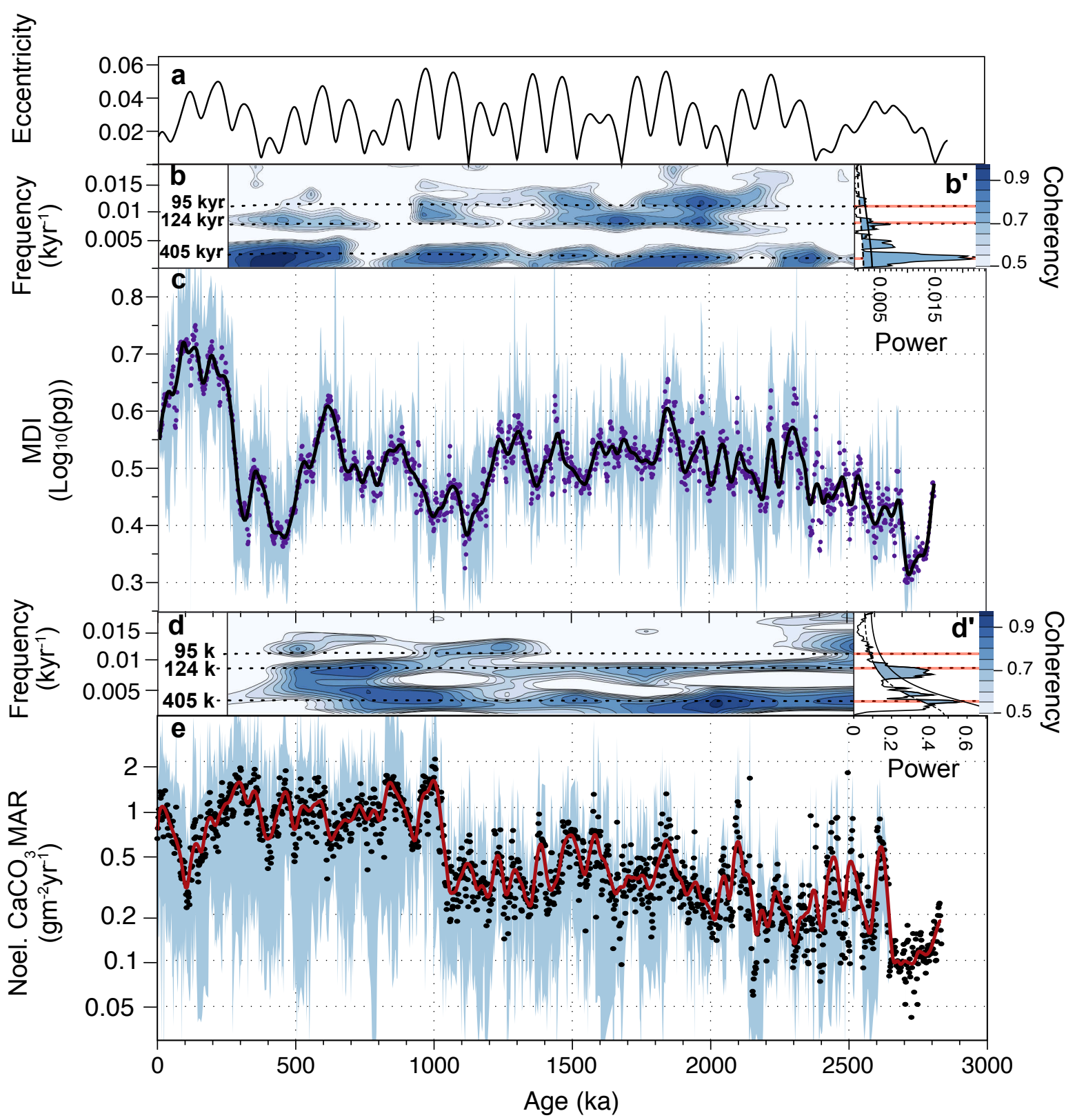

Figure 3: Eccentricity, coccolith morphological divergence, and Noëlaerhabdaceae $\mathrm{CaCO}_{3}$ mass accumulation rates. a: Earth's Level (CL) above 0.7); Horizontal dashed lines show eccentricity periods. b': MTM spectral analysis of detrended MDI stack. Shaded areas are above the $90 \% \mathrm{CL}$ (dashed line). Solid black line is 95\%CL. Frequency scale is aligned with b. c: MDI Stack (2 kyr resolution, see Methods). 


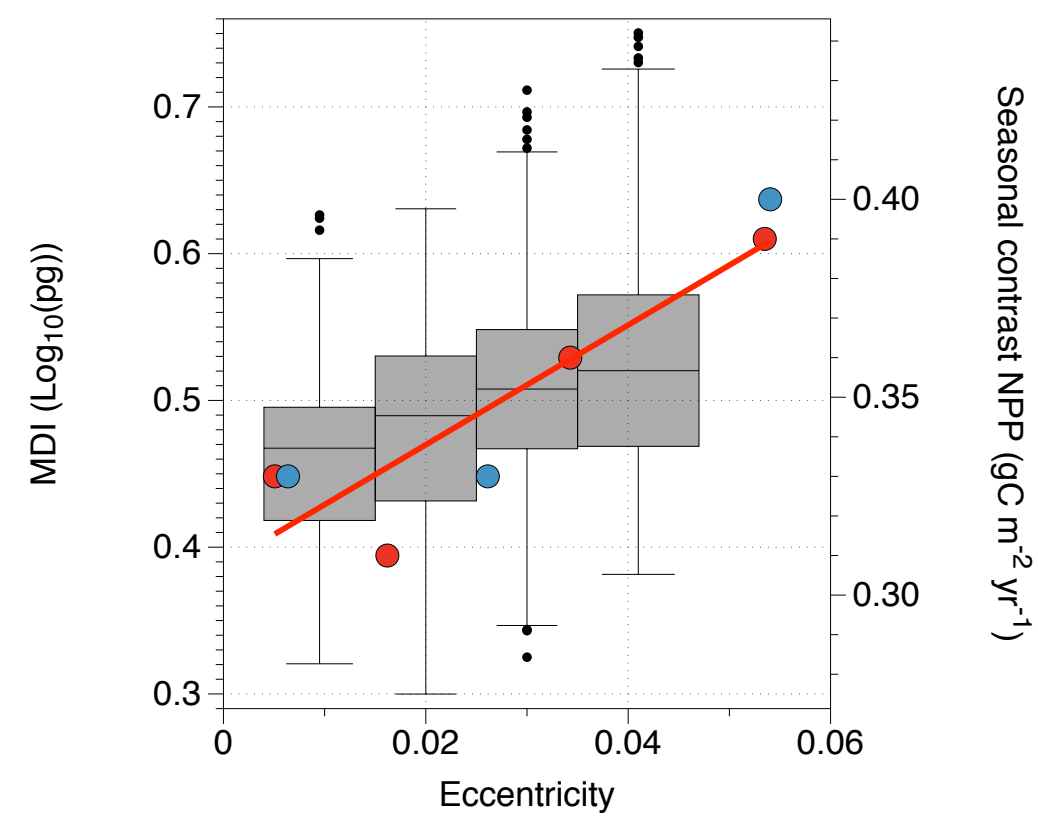

240 Figure 4: Morphological divergence index and modelled seasonality both increase with eccentricity. Box-whiskers plot of all MDI values,

241 sorted and binned by increasing low-pass filtered eccentricity, compared to the seasonal contrast of net primary production (maximum minus

242 minimum month) from numerical simulations (see Methods). Blue dots are model runs with perihelion in December (Pmax: $2222 \mathrm{ka}, 2265 \mathrm{ka}$,

243 and $2380 \mathrm{ka}$ ), red dots are runs with perihelion in June (Pmin: $2230 \mathrm{ka}, 2346 \mathrm{ka}, 2369 \mathrm{ka}$, and $2395 \mathrm{ka}$ ) - illustrating that eccentricity has a much

244 larger effect on seasonality than precession at a given eccentricity. 


\section{Coccolith data acquisition}

Over eight thousand samples were extracted from sediment cores for coccolithophore analysis at depth intervals to achieve a high stratigraphic resolution (0.5 to $2.3 \mathrm{kyr}$, Extended Data Table 1). Samples were prepared using the settling method ${ }^{2323}$ : sediments were disaggregated in water and suspensions were settled onto a 12x12 mm cover slip and mounted with Norland Optical Adhesive 74, with 8 cover slips per microscope slide. Some samples were prepared as independent duplicates. Two slides (16 samples) were placed at the same time onto the stage of an automated polarizing microscope (Leica DM6000). Following auto-focusing, 165 contiguous fields of view (with an area of $125 \mathrm{x} 125 \mu \mathrm{m}$ each) were imaged in each sample using a black and white SPOTFLEX camera (Diagnostic Instrument). SYRACO, a software program based on an Artificial Neural Network ${ }^{44}$, identified all specimens belonging to 33 groups of coccolithophore taxa in the images ${ }^{35}$. The gephyrocapsid specimens, the dominant group studied here, were classified into six distinct classes that were merged into one group. On average, 888 Noëlaerhabdaceae coccoliths were identified in each sample. Among other morphometric parameters, size and mass of the coccoliths were measured. Coccolith mass is measured using birefringence, following published state-of-the-art methods ${ }^{3336}$. The use of Artificial Intelligence in this type of work is essential because it is the only way to measure such a large number of specimens ( $>7$ million) in a reasonable time, and thus obtain the high-resolution multi-site records required for this study.

\section{Site-specific chronologies}

IMAGES core MD97-2140": The age model for Site MD97-2140" , on the Eauripik Rise in the Western Pacific Warm Pool, is based on tuning of a high-resolution planktonic foraminiferal Globigeronoides ruber $\delta$ : $\mathrm{O}$ record to the astronomically calibrated ODP Site $677 \delta$ \& $\mathrm{O}$. ruber record $^{\text {ss }}$, located in the eastern equatorial Pacific. This age model yields a chronology consistent with major micropaleontological (disappearance of G. ruber pink variety) and palaeomagnetic (Brunhes-Matuyama boundary) events ${ }^{30}$.

IMAGES core MD05-2920 ${ }^{\circ}$ :The age model for Site MD05-2920", on the southern bank of Manus Island, is based on ten Accelerator Mass Spectrometer (AMS) "C dates obtained from the surface-dwelling planktonic foraminifera G. ruber (white), and a correlation between the benthic foraminiferal $\delta{ }^{\prime} \mathrm{O}$ record and the reference LR04 benthic foraminiferal $\delta \mathrm{O}^{\mathrm{O}}$ stack's.

IMAGES core MD05-2930":The age model for Site MD05-2930", in the Coral Sea, is based on ten AMS "C measurements of G. ruber sensu stricto (ss), and on correlation of the MD05-2930 $\delta{ }^{\circledR O}$ G. ruber ss record with the LR04 benthic foraminiferal $\delta^{\circledR O}$ stack $^{\circledR}$.

IODP Site U1443: The age model for Site U1443, on the Ninetyeast Ridge in the southernmost Bay of Bengal, is based on correlation of physical properties data on the primary shipboard splice to the LR04 benthic foraminiferal $\delta^{\circledR} \mathrm{O}$ stack $^{18}$. Physical properties were measured onboard the RV Joides Resolution on archive halves from all holes at Site U1443, and correlation and splicing were based on magnetic susceptibility, natural gamma ray, and reflectance spectroscopy $b^{*}$ data ${ }^{4}$.

IODP Site U1448 ${ }^{\sharp}$ : The age model for Site U1448, in the Andaman Sea, is based on correlation of the Site U1448 Ti/Ca record, derived by XRay Fluorescence (XRF) core scanning, to the XRF Ti/Ca record of Indian National Gas Hydrate Program (NGHP) Site 17 - a very close site with age control based on a benthic foraminiferal oxygen isotope record tuned to the LR04 benthic foraminiferal $\delta^{\text {sis }} \mathrm{O}$ stack $^{1 s^{4 s+46} \text {. }}$

IODP Site U1446 ${ }^{4}$ : The age model for Mahanadi Basin Site U1446 is based on correlation of a high-resolution benthic foraminiferal oxygen isotope stratigraphy to the LR04 benthic foraminiferal $\delta{ }^{1} \mathrm{O}$ stack $^{18}$ (S.C. Clemens, unpublished data, pers. comm.)

IODP Site U1483 ${ }^{*}$ : The age model for Scott Plateau Site U1483 is based on the shipboard integrated Magneto-biostratigraphy, and on correlation of the U1483 L* record, which presents strong G/IG variability, to the LR04 benthic foraminiferal $\delta{ }^{18}$ stack $^{18}$. 
IODP Site U1485" The age model of the northern Papua Margin Site U1485 is based on correlation between the benthic foraminiferal $\delta^{18} \mathrm{O}$ record of this site and the LR04 benthic foraminiferal $\delta^{18} \mathrm{O}$ stack $^{18}$.

IODP Site U1486 ${ }^{47}$ : The age model of the upper $100 \mathrm{~m}$ (the last $1.6 \mathrm{Ma}$ ) of Site U1486, from the southern bank of Manus Island, is based on a correlation between the benthic foraminiferal $\delta^{18} \mathrm{O}$ record and the $\mathrm{LR} 04$ benthic foraminiferal $\delta^{18} \mathrm{O}$ stack ${ }^{18}$. Below $100 \mathrm{~m}$, the age model is based on the shipboard integrated magneto-biostratigraphy and correlation of the U1486 L* record (that shows strong G/IG variability) with the LR04 benthic foraminiferal $\delta^{18} \mathrm{O}$ stack $^{18}$.

\section{Construction of composite histograms of coccolith size and mass}

The distribution of coccolith mass values is skewed toward heavy values. We therefore used the logarithm of the mass to obtain a symmetrical mass distribution. Measurements were grouped into morphological bins of $0.1 \mu \mathrm{m}$ for coccolith length and $0.05 \log { }_{10}(\mathrm{pg})$ for coccolith mass in every sample. Samples were binned into 30-kyr time windows in each core, chosen such that it is larger than the length of a precession cycle (23-19 kyr). This will prevent any bias in the size/mass distribution resulting from changes in the relative abundance of large versus small gephyrocapsid species on precessional timescales ${ }^{48}$. Another advantage of using a 30 kyr time window is that the high number of measurements included in each $30 \mathrm{kyr}$ bin (on average 16650 measurements) make it extremely precise but easier to discern trends. To standardise each time window at each site, the numbers contained in each bin are divided by the total number of coccoliths in that time window and multiplied by 100 . To stack the records and produce evolutionary size histograms (Fig. 2a) and mass, all records are summed by bin and divided by the number of records.

\section{Morphological Divergence Index (MDI)}

In each sample, individual coccoliths were divided into two size classes: coccoliths longer and shorter than $3 \mu \mathrm{m}$. The average log $(\mathrm{mass})$ is calculated in both classes. MDI is the difference between the two averages (Extended Data Figure 2). The size of $3 \mu \mathrm{m}$ corresponds to the best cut-off value between the two modes $(2.8$ and $3.9 \mu \mathrm{m})$ of the size distribution. Other size cut-offs were tested $(2.9,3.25$ and $3.5 \mu \mathrm{m})$ without notable differences in the resulting MDI values and temporal trends. The records are resampled (by linear integration) at 2 kyr intervals for further analysis (time series, statistics, and stacking). A stacked record composed of all records is calculated for each time window. This stacked MDI reflects the variability seen in all individual records (Extended Data Figure 4). Because not all records cover the entire 2.8 Myr interval (3 records are over 2.3 Myr long, 3 are between 0.7 and 1.8 Myr long, and 3 are 0.4-0.6 Myr long), the stack is composed of more records in the younger part than in the older part. Because of the phase lag between MDI and eccentricity we use band-passed eccentricity (red line in Fig. 2b) to sort and bin DMI values used for Fig. 4.

\section{Mass accumulation rates}

Mass accumulation rates of Noëlaerhabdaceae coccoliths were estimated in seven cores (all cores excluding MD05-2530 and U1446) for which a quantitative sample preparation technique was applied ${ }^{33}$ : The samples were prepared by settling onto coverslips that were weighed before and after settling, the weight difference providing the amount of sediment deposited. The number and the mass of the Noëlaerhabdaceae is estimated by SYRACO. From these quantities it is possible to estimate the weight of Noëlaerhabdaceae per gram of sediment. Noëlaerhabdaceae CaCO MAR (only called MAR hereafter) is obtained by multiplying weight per gram by the sedimentation rate and the dry bulk density of sediment. The dry bulk density was estimated from continuous measurements of wet bulk density from gamma ray attenuation (GRAPE) and transformed by the linear relationship for each site between discrete shipboard measurements of wet bulk density and dry bulk density ${ }^{49}$ MARs for the 7 cores were stacked together after resampling each record at 2 kyr intervals (Fig. 3e), using the same method as for MDI. Other stacking methods, such 
as assembling LOESS-detrended records, were tried and produced consistent results. Differences exist between individual MAR records due to regional difference in coccolithophore productivity, export dynamics, and preservation (although only 2 cores, MD97-2140 and U1443, were retrieved from sediments deeper than $2000 \mathrm{~m}$ ). However, three common patterns emerge in all individual records: an increasing trend in MAR towards the present, a sharp stepwise increase at $\sim 1 \mathrm{Ma}$, and the clear presence of eccentricity cycles. Noëlaerhabdaceae coccolith flux (Extended Data Figure 5c) is calculated as the number of coccoliths per gram of sediment multiplied by the sedimentation rate.

\section{Time series analysis}

Time series analyses were performed using the software packages Analyseries ${ }^{50}$ and Acycle ${ }^{s i}$ on detrended records. Cross-spectral analyses were performed in Analyseries using Blackman-Turkey transforms ${ }^{52}$. For evolutive analyses (Fig. 3) a window of 500 kyr (250 data points) and a step of $100 \mathrm{kyr}$ was used. Coherence values above 0.56 are above the $80 \%$ confidence level (Fig. 2b). Spectral analyses were performed with the Multi Taper Method (MTM) ${ }^{\text {ss }}$ with both evolutive and entire series (Extended Data Figure 1). Spectral properties are similar in all individual MDI records, and show that the absence of precession (19-23 kyr) and obliquity ( $41 \mathrm{kyr}$ ) is not a result of chronological bias in constructing the stack that would have smoothed the record. Each record has a $\sim 2 \mathrm{kyr}$ resolution with a precise independent age model. The absence of precession and obliquity is therefore a common and robust feature of all of the MDI series as well as the stacked record.

\section{Low-pass filters}

We designed $2^{\text {nd }}$ order low-pass filters in order to reproduce the effect of the time needed for a new evolved species to fully succeed (200 kyr for E. huxleyi). We transformed the following classical low-pass filter complex transfer function $H$ :

$H(j \omega)=\frac{A}{1+\frac{j \omega}{Q \omega_{0}}-\omega^{2}}$

(where $\mathrm{A}$ is the amplitude, $\mathrm{Q}$ is the quality factor, $\omega$ is the angular frequency $2 \pi f$, ( $\mathrm{f}$ the frequency)) in its associated differential equation: $\frac{d^{2} y}{d t^{2}}+\frac{\omega_{0}}{Q} \frac{d y}{d t}+\omega_{0}^{2} y=\omega_{0}^{2} x \quad$ where $\mathrm{y}$ is the output series and $\mathrm{x}$ the input series.

We solved it numerically as follow:

$y_{t}=\frac{1}{1+\frac{\omega_{0}}{Q}+\omega_{0}^{2}}\left(\left(2+\omega_{0}\right) y_{t-1}-y_{t-2}\right) A \omega_{0}^{2} x_{t}$

Two configurations have been chosen: one produces a delay of $200 \mathrm{kyr}$ for the new species' success, the second produces a delay of $130 \mathrm{kyr}$ (Extended Data Figure 8a). To obtain those delays, we used the following values:

First case (delay of $200 \mathrm{kyr}), \omega_{0}=0.021, \mathrm{Q}=1, \mathrm{~A}=1$

Second case (delay of $130 \mathrm{kyr}), \omega_{0}=0.035, \mathrm{Q}=1.02, \mathrm{~A}=0.65$

The delay of $200 \mathrm{kyr}$ corresponds to the time between the First Appearance Datum (FAD) and the beginning of the acme (BA) of E. huxleyi ${ }^{17}$. The FAD of this species is well documented because its characteristic T shape elements are a morphological feature that appeared suddenly, without gradation. The other Gephyrocapsa species have been described using criteria that are subject to gradation between species: coccolith length, size of the central opening, and orientation of the bridge ${ }^{54}$. For example, the FAD of a typical G. ercisonii, (a small gephyrocapsid) that appeared at about the same time as E. huxleyi ${ }^{3}$ is not reported precisely because it evolved progressively from G. caribbeanica (a mid-size species). It is interesting to note that the FAD and the BA of E. huxleyi occurred similarly in times of eccentricity decrease, but two cycles apart. The intermediate cycle may have been too high to allow E. huxleyi to begin its dominance. This may not have been the case for other species under different orbital configurations. This is why we did a filter with a different configuration, which produces a delay of about one eccentricity 
cycle between a FAD and a BA. In order to express the response of those filters, we built their Bode magnitude plots, expressing the frequency response, and their Bode phase plots, expressing the phase shift (Extended Data Figure 8b, c).

\section{Model Description}

To simulate changes in Net Primary Production (NPP) related to changes in eccentricity we used the Earth System Model IPSL-CM5A2 that simulates the interactions between ocean, atmosphere, land and ice. The following section provides a brief description of model components and experiments setup. We then describe the model behaviour at low eccentricity and discuss how the large-scale ocean-atmosphere circulation at high eccentricity in our simulations compare to previous modelling studies.

The IPSL-CM5A2 coupled model is a combination of the LMDz5A atmospheric model ${ }^{s}$, the ORCHIDEE ${ }^{s 6}$ land surface model and the NEMOv3.6 oceanic model ${ }^{s}$. The NEMO model includes an ocean dynamic component $\left(\mathrm{OPA}^{s s}\right)$, a sea-ice thermodynamics model (LIM2 $\left.{ }^{s}\right)$ as well as a biogeochemistry model (PISCES-v2 $2^{\circ}$ ) and has an horizontal resolution of $2^{\circ}$ by $2^{\circ}$ (refined to $0.5^{\circ}$ in the tropics) and 31 vertical levels, whose thickness increases from $10 \mathrm{~m}$ at the surface to $500 \mathrm{~m}$ at the bottom. The atmospheric grid has a horizontal resolution of $1.875^{\circ}$ in latitude by $3.75^{\circ}$ in longitude with 39 vertical levels. The ocean-atmosphere coupling is ensured by the OASIS coupler ${ }^{\infty}$ that interpolates and exchange variables between the two components. Detailed description of IPSL-CM5A2 and performances in simulating pre-industrial climate can be found in references 61,62. PISCES-v2 simulates the main oceanic biogeochemical cycles (C, P, Si, N and Fe) and has a simple representation of the lower trophic levels of the marine ecosystem ${ }^{\varsigma}$, with two phytoplankton (nannophytoplankton and diatoms) and two zooplankton (micro- and meso-zooplankton) size classes and five limiting nutrients $\left(\mathrm{Fe}, \mathrm{NO}_{3}, \mathrm{NH}_{4}^{+}, \mathrm{Si}\right.$ and $\mathrm{PO}_{4}{ }^{3}$ ). Phytoplankton growth is controlled by nutrients, light availability, and water temperature. In the version of the model we used, river supply to the ocean of all elements apart from DIC and alkalinity is taken from the GLOBAL-NEWS2 data sets ${ }^{63}$ and does not vary from one simulation to another. Model parameterizations are detailed in reference 6 .

Simulations were performed for seven early Pleistocene time slices and differ only by their respective orbital parameters (Extended Data Table 2, Figure 2). The time slices were chosen in order to target the signal produced by the $405-\mathrm{kyr}$ eccentricity cycle. Land-sea mask, ice-sheets configuration as well as $\mathrm{CO}_{2}$ and other greenhouse gases concentrations are set at pre-industrial values. Each simulation was started from the same equilibrated pre-industrial simulation ${ }^{\prime 2}$ and was run for 500 years. NPP is integrated over the whole water-column and averaged over the last 100 model years.

At low eccentricity (EminPmax and EminPmin) the eastern Indian ocean surface dynamics is forced by the summer westerlies that blow northward over the Bay of Bengal (Extended Data Figure 6f), associated with high precipitation over India and the Himalayan foreland region, while strong easterlies are recorded south of the equator. Winds force strong westward surface currents along the equator and south of Sumatra Island that generate upwelling (Extended Data Figure 7b). The latter advects nutrients to the surface (Extended Data Figure 7a) and triggers high productivity during summer. This peak productivity contributes to the strong seasonal cycle in this region. The winds reverse during boreal winter, triggering a second productivity bloom of lesser intensity (not shown). The productivity minimum is recorded during late spring when low-level winds along the equator are weak westerlies that favour downwelling and prevent strong convective mixing, which results in lower nutrient content within the surface layer of the ocean. The seasonal cycle of productivity in this region is very similar to the cycle simulated for the present-day $\mathrm{EIO}^{\star}$. 
At high eccentricity, the simulated patterns of atmosphere-ocean circulation and surface ocean physical state (Extended Data Figure 6g-j and 8b,

c) are in line with previous modelling study under similar orbital configurations ${ }^{656}$. In addition, our simulations also illustrate how these changes impact the seasonal productivity cycle. The increasing amplitude of the seasonal cycle in the surface ocean at high eccentricity is probably not limited to the IPWP area. For example, Erb et al.$^{68}$ also simulate enhancement of the surface ocean temperature cycle at high eccentricity in the Eastern Equatorial Pacific, with higher amplitude that in the Western Equatorial Pacific.

\section{Methods references}

32 Beaufort, L. Adaptation of the random settling method for quantitative studies of calcareous nannofossils. Micropaleontology 37, 415$418(1991)$.

Beaufort, L., Barbarin, N. \& Gally, Y. Optical measurements to determine the thickness of calcite crystals and the mass of thin carbonate particles such as coccoliths. Nat. Protoc. 9, 633-642, doi:10.1038/nprot.2014.028 (2014).

Beaufort, L. \& Dollfus, D. Automatic recognition of coccolith by dynamical neural network. Mar. Micropaleontol. 51, 57-73, doi : 10.1016/j.marmicro.2003.09.003 (2004).

Barbarin, N. La reconnaissance automatisée des nannofossiles calcaires du Cénozoique. Doctorat thesis, Aix-Marseille Université, (2014).

Beaufort, L. Weight estimates of coccoliths using the optical properties (birefringence) of calcite. Micropaleontology 51, 289-298, doi 10.2113/gsmicropal.51.4.289 (2005).

de Garidel-Thoron, T., Rosenthal, Y., Bassinot, F. C. \& Beaufort, L. Stable sea surface temperatures in the western Pacific warm pool over the past 1.75 million years. Nature 433, 294-298, doi: 10.1038/nature03189 (2005).

Shackleton, N. J. et al. An alternative astronomical calibration of the lower Pleistocene timescale based on ODP Site 677. T. Rse. Earth 81, 251-261, doi: 10.1017/S0263593300020782 (1990).

Carcaillet, J. T., Thouveny, N. \& Bourlès, D. L. Geomagnetic moment instability between 0.6 and 1.3 Ma from cosmonuclide evidence. Geophys. Res. L. 30, 1792, doi: 10.1029/2003GL017550 (2003).

Beaufort, L. \& Shipboard Scientific Party. MD148/PECTEN. (Institut Polaire Francais, 2005).

Tachikawa, K. et al. The precession phase of hydrological variability in the Western Pacific Warm Pool during the past 400 ka. Quaternary Sci. Rev. 30, 3716-3727, doi: 10.1016/j.quascirev.2011.09.016 (2011).

Regoli, F. et al. Progressive shoaling of the equatorial Pacific thermocline over the last eight glacial periods. Paleoceanography 30, 439455, doi: 10.1002/2014PA002696 (2015).

Clemens, S. C., Kuhnt, W., LeVay, L. J. \& the Expedition 353 Scientists Indian monsoon rainfall. IODP Preliminary Report 353, doi: 10.14379/iodp.pr.353.2015 (2015).

Clemens, S. C. Site U1443. - Proceedings of the International Ocean Discovery Program; Indian monsoon rainfall; Expedition 353 of the riserless drilling platform from and to Singapore; Sites U1443-U1443, 29 November 2014-29 January 2015 353, 41-41 (2016). 9, 4702, doi: 10.1038/s41467-018-07076-2 (2018).

Gebregiorgis, D. et al. What can we learn from X-ray fluorescence core scanning data? A paleomonsoon case study. Geochem. Geophy. Geosy. 21, e2019GC008414, doi: 10.1029/2019GC008414 (2020).

Rosenthal, Y., Holbourn, A. E., Kulhanek, D. K. \& the Expedition 363 Scientistsin IODP proceeding Vol. 363 (ed IODP) 69 (Texas A\&M University, College Station TX, USA, 2017). 

245-272 (Kluwer Academic/Plenum Publisher, 1999).

Lyle, M. Vol. 18 (2003). 10.1029/96EO00259 (1996). 22, doi: 10.1016/j.cageo.2019.02.011 (2019). 10.1016/S0377-8398(96)00028-X (1997). Clim. Dyn. 40, 2167-2192, doi: 10.1007/s00382-012-1411-3 (2013). Institut Pierre-Simon Laplace (IPSL), France, 1288-1161 (2008). Res. Oceans 102, 12609-12646, doi: 10.1029/97JC00480 (1997). (2012). 2123-2165, doi: 10.1007/s00382-012-1636-1 (2013). doi: 10.5194/gmd-13-3011-2020 (in review).

Softw. 25, 837-853, doi: 10.1016/j.envsoft.2010.01.007 (2010). Sci. Rev. 188, 121-135, doi: 10.1016/j.quascirev.2018.03.025 (2018).

Beaufort, L., Bassinot, F. C. \& Vincent, E. in Reconstructing Ocean History: a window into the future (eds F. Abrantes \& A.C. Mix)

Paillard, D., Labeyrie, L. \& Yiou, P. Macintosh program performs time-series analysis. Eos Trans. AGU, 77, 379, doi:

Li, M., Hinnov, L. \& Kump, L. Acycle: Time-series analysis software for paleoclimate research and education. Comput. Geosci. 127, 12-

Blackman, R. B. \& Tukey, J. W. The measurement of power spectra from the point of view of communications engineering-Part I. Bell Syst. Tech. J. 37, 185-282, doi: 10.1002/j.1538-7305.1958.tb03874.x (1958).

Thomson, D. J. Spectrum estimation and harmonic analysis. Proc. IEEE 70, 1055-1096, doi: 10.1109/PROC.1982.12433 (1982). Bollmann, J. Morphology and biogeography of the Gephyrocapsa coccoliths in Holocene sediments. Mar. Micropaleontol. 29, 319-350,

Hourdin, F. et al. Impact of the LMDZ atmospheric grid configuration on the climate and sensitivity of the IPSL-CM5A coupled model.

Krinner, G., Ciais, P., Viovy, N. \& Friedlingstein, P. A simple parameterization of nitrogen limitation on primary productivity for global vegetation models. Biogeosciences Discuss. 2, 1243-1282, doi : 10.5194/bgd-2-1243-2005 (2005).

Madec, G. \& Nemo, T. NEMO ocean engine. Note du Pôle de modélisation de l'Institut Pierre $\square$ Simon Laplace 27 (2015).

Madec, G. NEMO reference manual, ocean dynamics component: NEMO-OPA. Preliminary version. Note du Pole de modélisation,

Fichefet, T. \& Maqueda, M. M. Sensitivity of a global sea ice model to the treatment of ice thermodynamics and dynamics. J. Geophys.

Valcke, S. et al. Coupling technologies for earth system modelling. Geosci. Model Dev. 5, 1589-1596, doi: 10.5194/gmd-5-1589-2012

Dufresne, J.-L. et al. Climate change projections using the IPSL-CM5 Earth System Model: from CMIP3 to CMIP5. Clim. Dyn. 40,

Sepulchre, P. et al. An Earth System Model designed for long simulation of past and future climates. Geosci. Model Dev. 13, 3011-3053,

Mayorga, E. et al. Global nutrient export from WaterSheds 2 (NEWS 2): model development and implementation. Environ. Model.

Koné, V., Aumont, O., Lévy, M. \& Resplandy, L. Physical and biogeochemical controls of the phytoplankton seasonal cycle in the Indian Ocean: A modeling study. In Indian Ocean Biogeochemical Processes and Ecological Variability (eds J.D. Wiggert, R.R. Hood, S.A. Naqvi, K.H. Brink and S.L. Smith) 185, 350, doi: 10.1029/2008GM000700 (2009).

Bosmans, J. et al. Response of the Asian summer monsoons to idealized precession and obliquity forcing in a set of GCMs. Quaternary

Braconnot, P. \& Marti, O. Impact of precession on monsoon characteristics from coupled ocean atmosphere experiments: changes in Indian monsoon and Indian ocean climatology. Mar. Geol. 201, 23-34, doi: 10.1016/S0025-3227(03)00206-8 (2003).

Prescott, C., Haywood, A., Dolan, A., Hunter, S. \& Tindall, J. Indian monsoon variability in response to orbital forcing during the late Pliocene. Global Planet. Change 173, 33-46, doi: 10.1016/j.gloplacha.2018.12.002 (2019). 
Erb, M. P. et al. Response of the equatorial pacific seasonal cycle to orbital forcing. J. Climate 28, 9258-9276, doi: 10.1175/JCLI-D-15$0242.1(2015)$

Chen, M.-T. \& Beaufort, L. Exploring quaternary variability of the east Asia monsoon, Kuroshio Current, and western Pacific warm pool systems: High-resolution investigations of paleoceanography from the IMAGES III (MD106) IPHIS cruise. TERRESTRIAL ATMOSPHERIC AND OCEANIC SCIENCES 9, 129-142 (1998).

Gartner, S. Paleoceanography of the mid-Pleistocene. Mar. Micropaleontol. 13, 23-46, doi: 10.1016/0377-8398(88)90011-4 (1988). Pujos, A. \& Giraudeau, J. Distribution of Noelaerhabdaceae (calcareous nannofossils) in the upper and middle Quaternary of the Atlantic and Pacific oceans. Oceanol. Acta 16, 349-362 (1993).

\section{Acknowledgments}

This paper is a contribution of the Climate research group at CEREGE. This research uses samples provided by the IODP, which is sponsored by the U.S. National Science Foundation and participating countries under management of Joint Oceanographic Institutions, Inc. We thank the shipboard participants of IODP Expeditions 353 and 363 and IMAGES Expeditions 3 and 13. The authors acknowledge French ANR projects CALHIS (LB), iMonsoon (CTB), AMOR (YD), and INSU project CALVE (CTB) which provided funding for this work. IODP-France provided post-cruise funding to LB and CTB. A. Fruy and S. Sergi are thanked for sample preparation assistance. We thank the CEA/CCRT for providing access to the HPC resources of TGCC under the allocation 2019-A0070102212 made by GENCI.

\section{Author Contributions}

LB designed the study. LB, YG, NB and MT developed automated artificial intelligence methods. LB, CTB, JCM, PC, EG, and SB prepared samples and/or generated data. ACS designed and ran the model simulations, in collaboration with YD. LB and CTB analysed the morphometric data. LB, CTB, ACS, BSM, YD, and YR discussed interpretations. LB, CTB and ACS wrote the manuscript with important contributions from BSM, YD, and YR.

\section{Additional Information}

Correspondence and requests for materials should be addressed to Luc Beaufort (beaufort@ cerege.fr). Reprints and permissions information is available at www.nature.com/reprints.

\section{Competing interest declaration}

The authors declare no competing interests. 


\begin{tabular}{|c|c|c|c|c|c|c|c|c|c|}
\hline Site & Expedition & Longitude & Latitude & $\begin{array}{l}\text { Water } \\
\text { Depth } \\
\text { (m) }\end{array}$ & Biome & $\begin{array}{l}\text { Record } \\
\text { length } \\
\text { (kyr) }\end{array}$ & $\begin{array}{l}\text { Mean } \\
\text { Resolution } \\
\text { (kyr) }\end{array}$ & $\begin{array}{l}\text { Number of } \\
\text { samples }\end{array}$ & $\begin{array}{l}\text { Number of } \\
\text { Measurements }\end{array}$ \\
\hline U1446 & IODP 353 & $85^{\circ} 441$ & $19^{\circ} 050 \mathrm{~N}$ & 1440 & INDE & 468 & 0.5 & 952 & 222119 \\
\hline U1448 & IODP 353 & $93^{\circ} 00.00$ & $10^{\circ} 38.03 \mathrm{~N}$ & 1096 & MONS & 716 & 1.1 & 624 & 617138 \\
\hline U1443 & IODP 353 & $90^{\circ} 21.71$ & $5^{\circ} 23.01 \mathrm{~N}$ & 2940 & MONS & 2818 & 1.6 & 1717 & 1337793 \\
\hline MD97-2140 & IMAGES 3 & $141^{\circ} 45.49$ & $2^{\circ} 02.59 \mathrm{~N}$ & 2547 & $\begin{array}{l}\text { WAR } \\
\text { M }\end{array}$ & 1758 & 1.4 & 1241 & 540523 \\
\hline U1486 & IODP 363 & $144^{\circ} 36.08$ & $2^{\circ} 22.34 \mathrm{~S}$ & 1332 & $\begin{array}{l}\text { WAR } \\
\text { M }\end{array}$ & 2661 & 2.2 & 1195 & 1004860 \\
\hline MD05-2920 & IMAGES 13 & $144^{\circ} 32$ & $2^{\circ} 51.48 \mathrm{~S}$ & 1843 & $\begin{array}{l}\text { WAR } \\
\text { M }\end{array}$ & 387 & 1.1 & 353 & 436984 \\
\hline U1485 & IODP 363 & $142^{\circ} 47.59$ & $3^{\circ} 06.16 \mathrm{~S}$ & 1145 & SUND & 535 & 0.9 & 587 & 580612 \\
\hline MD05-2930 & IMAGES 13 & $146^{\circ} 15.73$ & $10^{\circ} 25.30 \mathrm{~S}$ & 1490 & AUSE & 793 & 2.1 & 372 & 620736 \\
\hline U1483 & IODP 363 & $121^{\circ} 5.24$ & $13^{\circ} 05.24 \mathrm{~S}$ & 1733 & ISSG & 2332 & 2.3 & 994 & 1777406 \\
\hline & & & & & & & Average $=1.6$ & Sum $=8035$ & Sum=7 138171 \\
\hline
\end{tabular}

Extended Data Table 1: Characteristics of the nine marine records used in this study. Biome $\operatorname{code}^{20}:$ INDE $=$ Eastern India Coastal province, and Indian Tropical Oceans (Figure 1).

\begin{tabular}{|l|l|l|l|l|l|}
\hline $\begin{array}{c}\text { Configuration } \\
\text { (kyr) }\end{array}$ & Eccentricity & Precession & $\begin{array}{c}\text { Longitude of } \\
\text { perihelion ( }\end{array}$ & Obliquity () & $\begin{array}{c}\text { Mean YCR at } \\
\text { Equator (W.m } \mathbf{~}^{-2}\end{array}$ \\
\hline C2222 (EmaxPmax) & 0.054 & 0.054 & 87 & 23.73 & 74 \\
\hline C2230 (EmaxPmin) & 0.053 & -0.037 & 315 & 23.84 & 83 \\
\hline C2265 & 0.026 & 0.024 & 115 & 24.28 & 59 \\
\hline C2346 & 0.034 & -0.033 & 287 & 24.27 & 62 \\
\hline C2369 & 0.016 & -0.015 & 256 & 22.26 & 52 \\
\hline C2380 (EminPmax) & 0.006 & 0.006 & 77 & 23.74 & 37 \\
\hline C2395 (EminPmin) & 0.005 & -0.003 & 310 & 23.42 & 39 \\
\hline
\end{tabular}

507 Extended Data Table 2: Summary of orbital parameters ${ }^{19}$ used for each simulation and Mean Yearly Contrast of Radiation at Equator $\left(\mathrm{Wm}^{2}\right)$ derived from IPSL-CM5A2 (see Methods). 
a - Cross BT : Ecc. vs Size stack
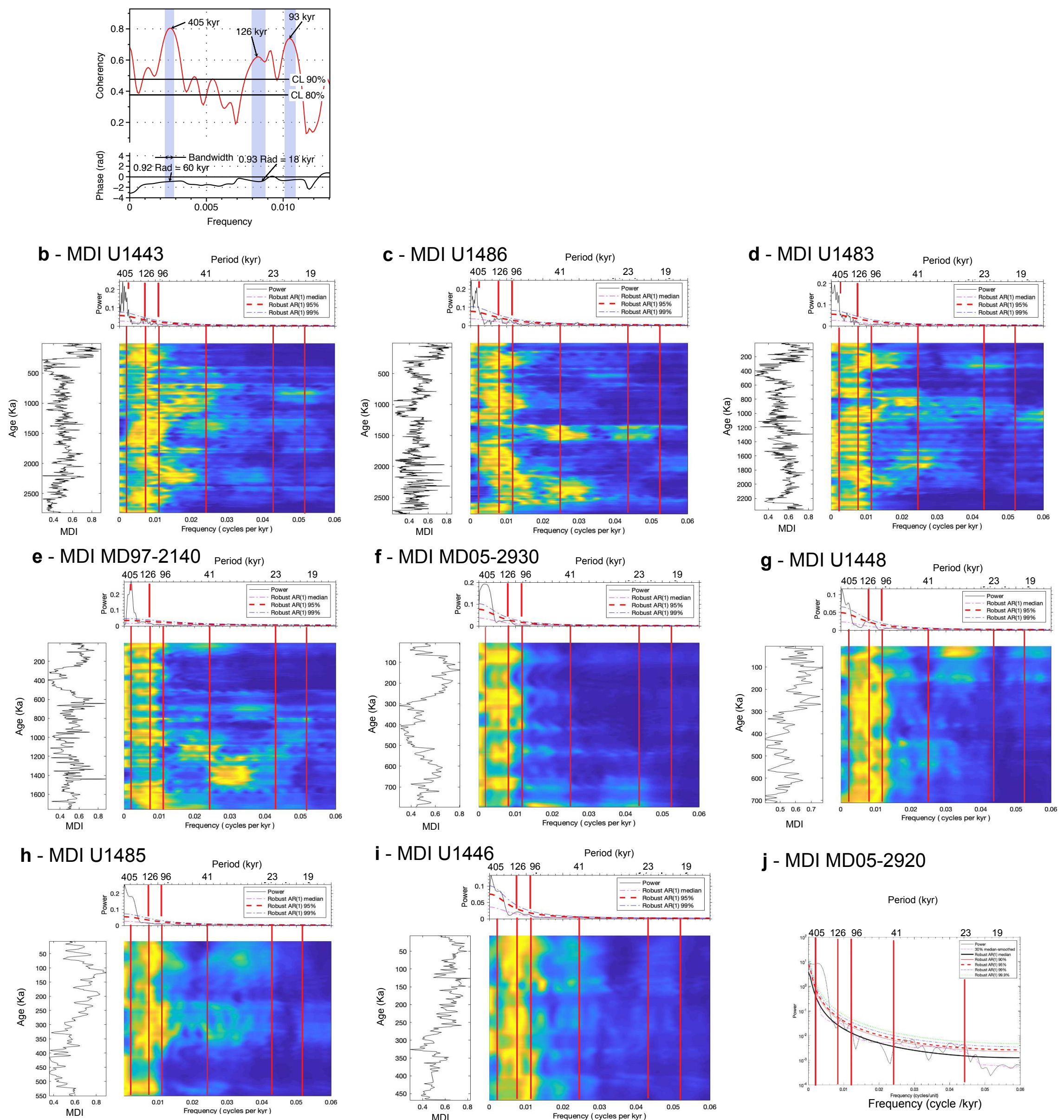

j - MDI MD05-2920

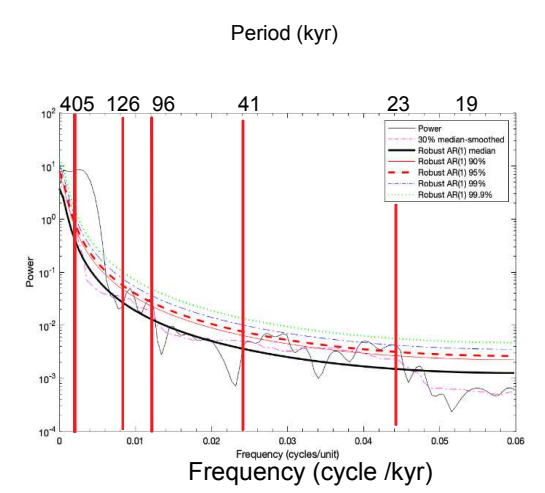

Extended Data Figure 1: a: Cross-spectral analysis between eccentricity and stacked average coccolith length. Top: coherency; Bottom: phase 


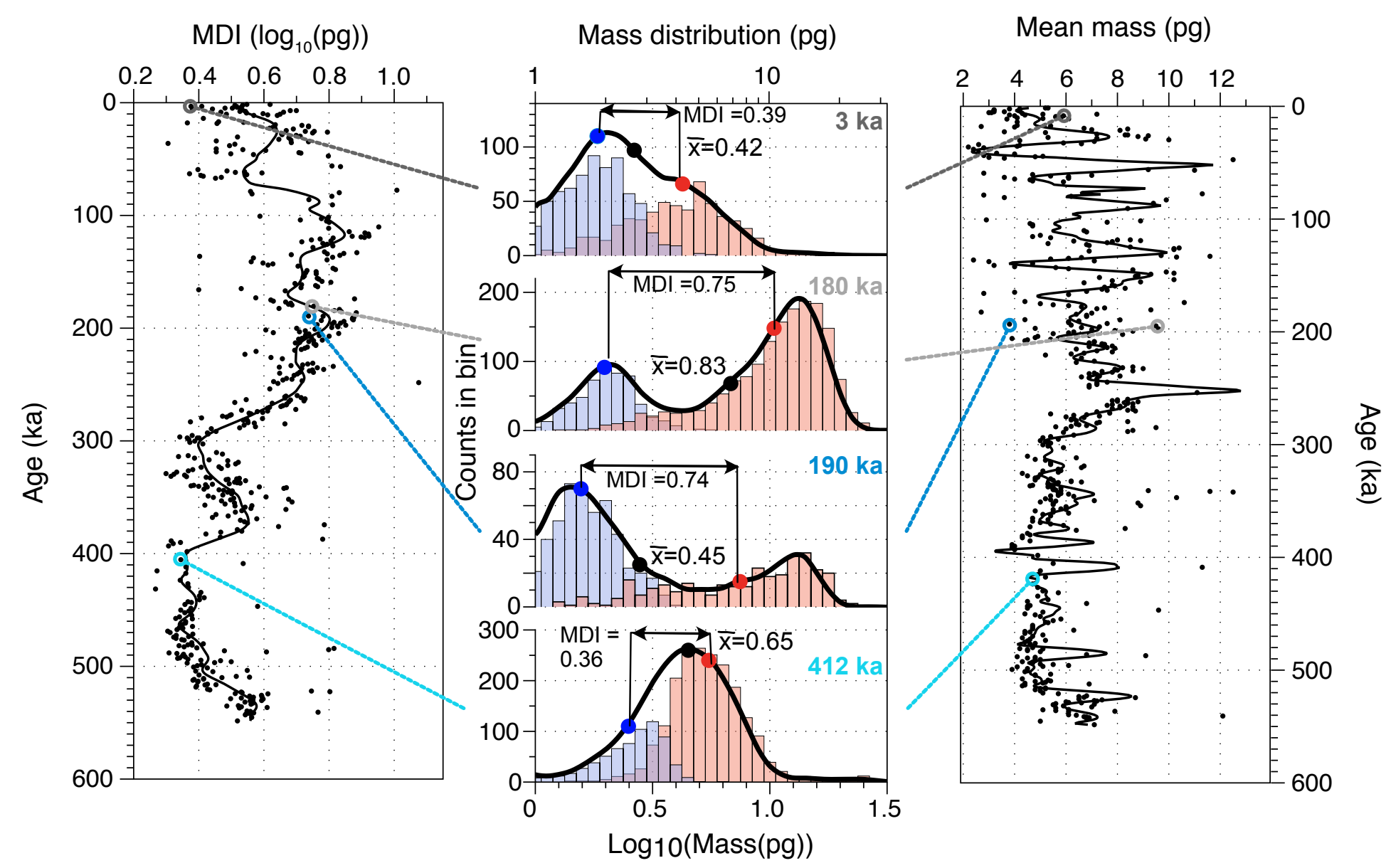

514 Extended Data Figure 2: Schematic illustrating how MDI is calculated (also see Methods), and how it represents morphological diversity,

515 using data from Site U1485 as an example. In each sample, two size classes are created: coccoliths shorter and longer than $3 \mu \mathrm{m}$ (blue and red

516 histograms). The average $\log$ (mass) is calculated in both classes (blue and red dots on the histograms). MDI is the difference between these two

517 averages. Thus, MDI can differ substantially from average coccolith mass of the whole population (black dots on mass distribution plots), and

518 two samples can have a similar MDI but very different average mass and mass distributions (e.g., examples at 180 ka and 190 ka), or very

519 different MDI but similar averages (e.g., 3 ka vs $190 \mathrm{ka}$ ). In this way, MDI isolates morphology variability that results from evolutionary

520 contractions and dilations in the number of different morphotypes present within the population. 

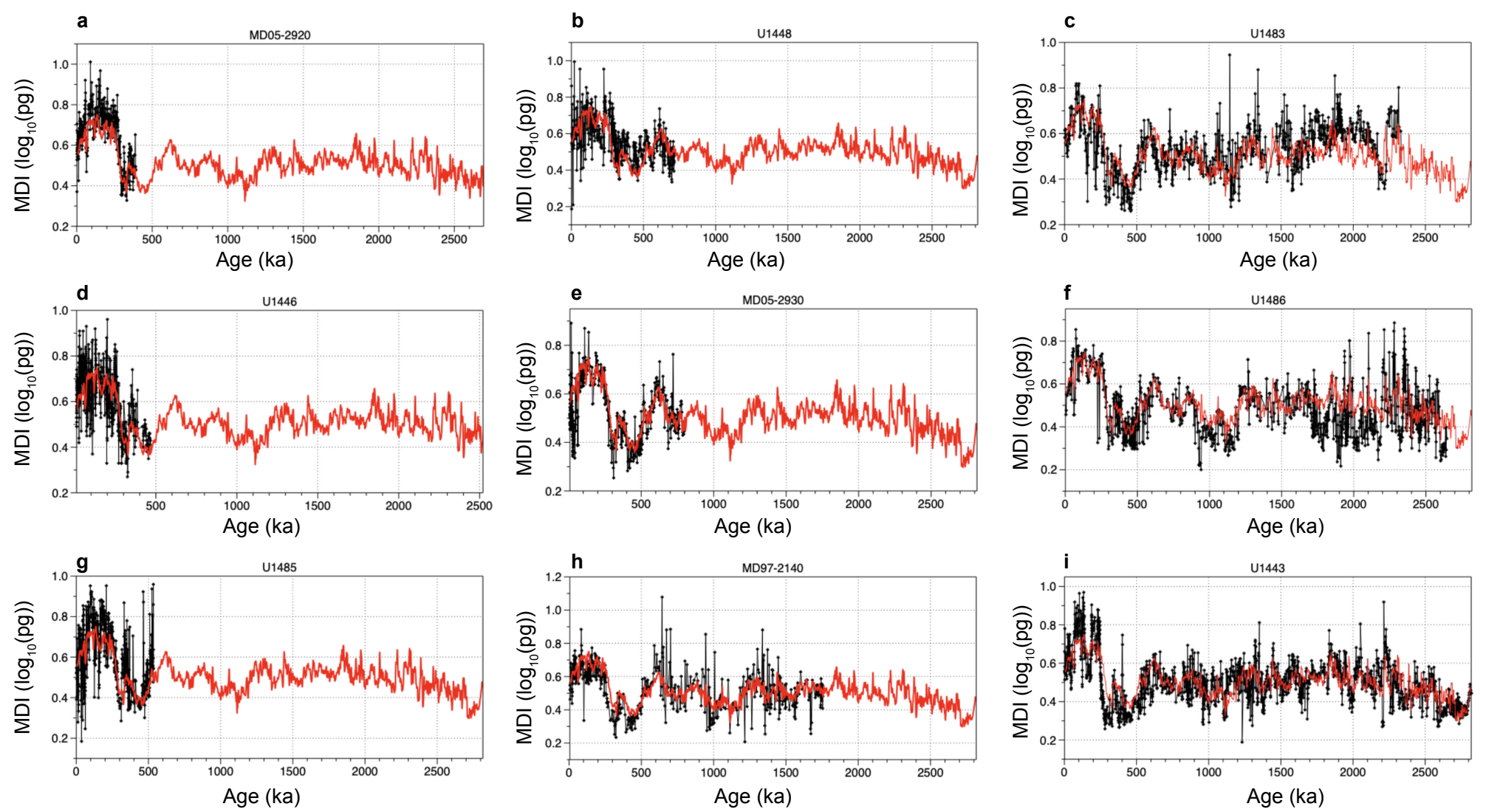

Extended Data Figure 3: Individual MDI records for each site (black lines and points) plotted with the stacked MDI record (red line). Pearson

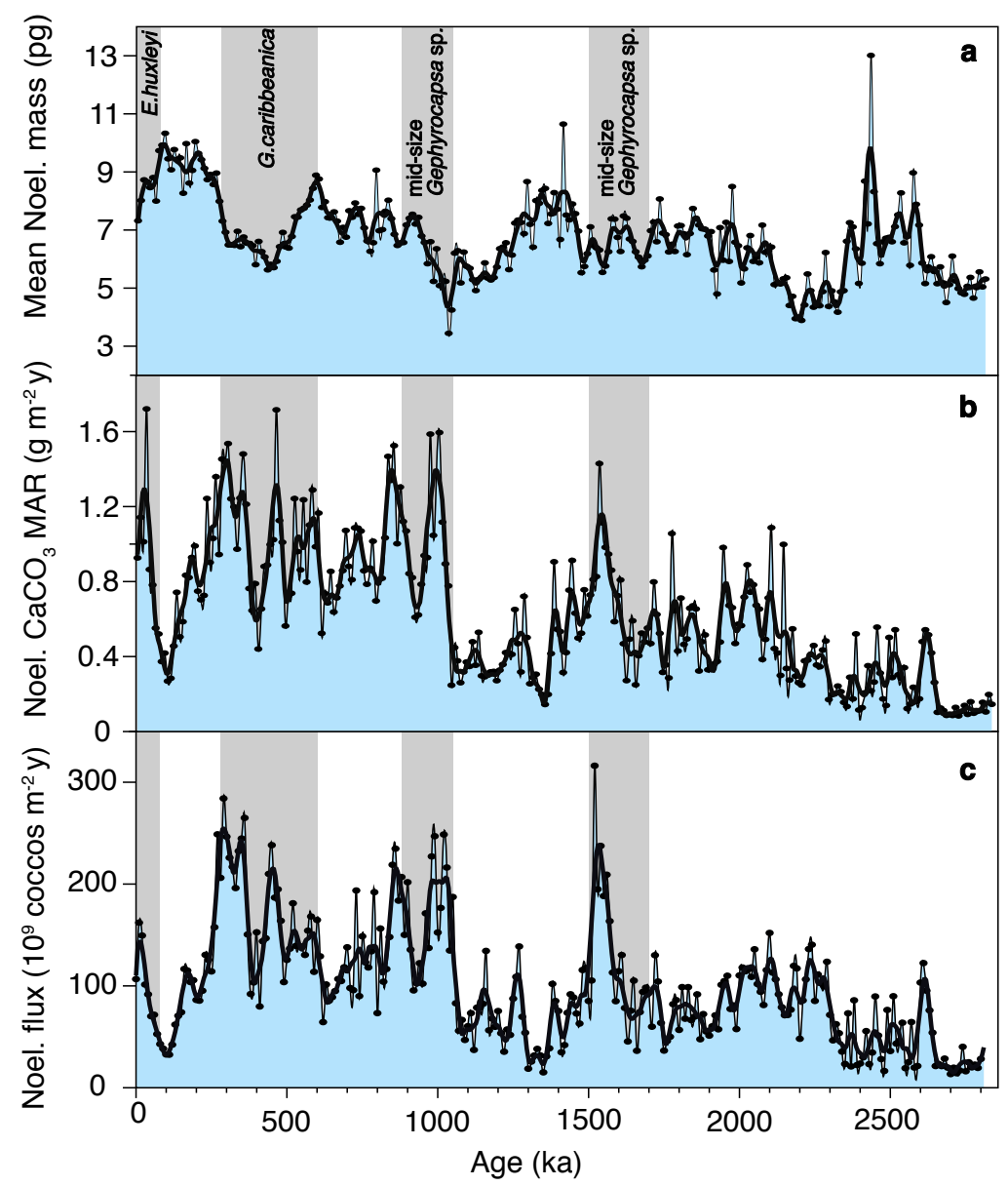

Extended Data Figure 4: Figure comparing stacked records, binned into 10-kyr intervals, of Noëlaerhabdaceae average coccolith mass (a),

represent four described acmes of mid-size Noëlaerhabdaceae species ${ }^{15177^{2}, 0,1}$. 

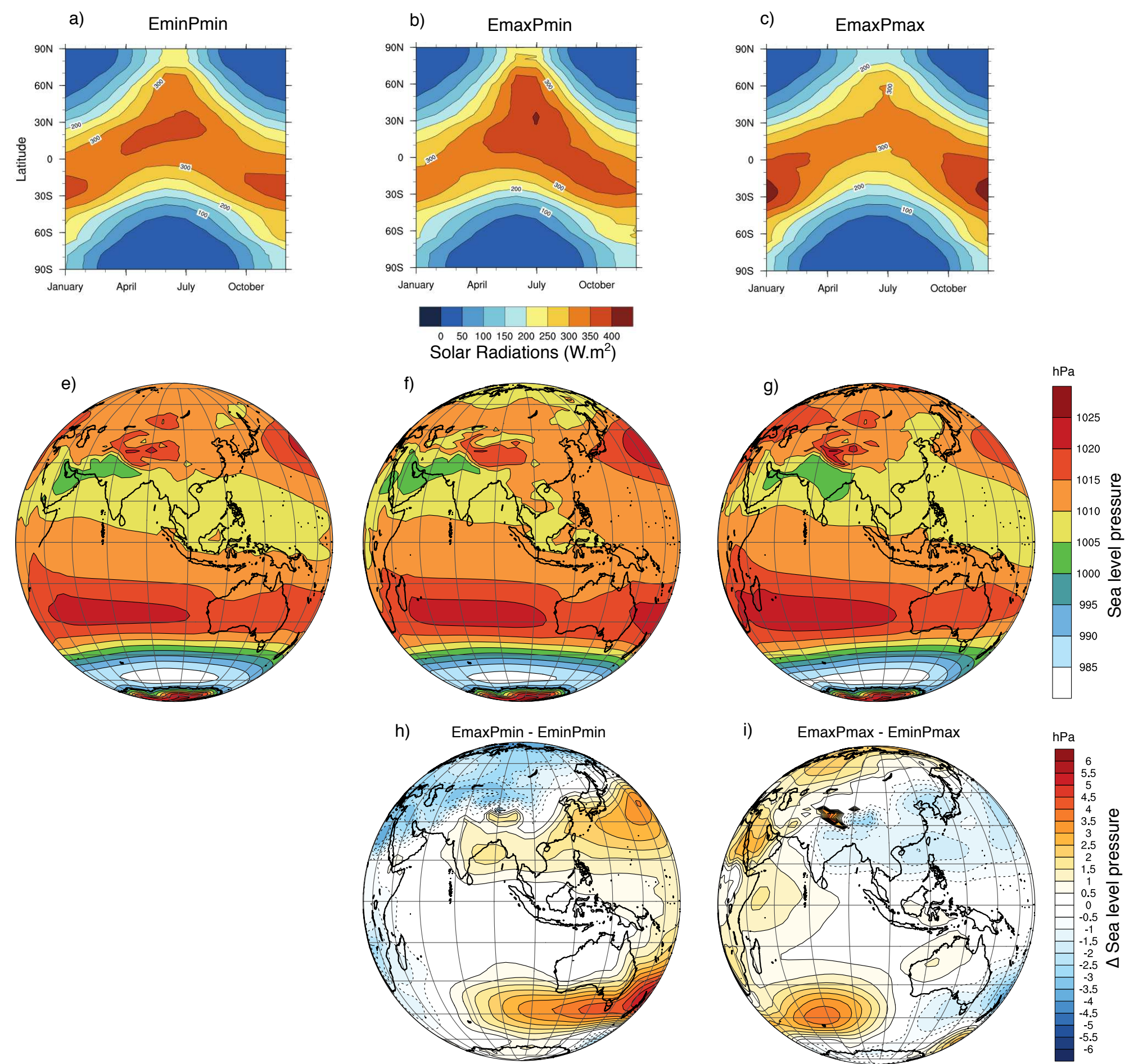

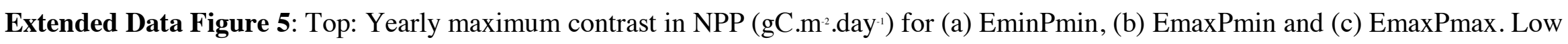
eccentricity values minimise the amplitude of precession variability (Extended Data Figure 7a-c), thus we only show results for minimum precession value at minimum eccentricity (EminPmin) but the reader can consider those results to be similar for the EminPmax simulation. (d) and (e) represent the anomaly of yearly maximum contrast in NPP. At EmaxPmax, the eastern equatorial Indian Ocean exhibits moderate seasonality (a) due to inhibition of the summer productivity induced by lower nutrient concentrations in this area (Extended Data Figure 8a). In this case, high productivity areas during boreal summer are shifted to south-west of India. Bottom: Late summer (JASO) low-level winds for (f) EminPmin (g) EmaxPmin (h) EmaxPmax simulations. (i) and (j) represent the anomaly in late summer low-level winds. At EmaxPmax the north-equatorial westerlies (c, e) are confined to south of $10^{\circ} \mathrm{N}$ due to the extension above India of the low-pressure area (Figure 1). 

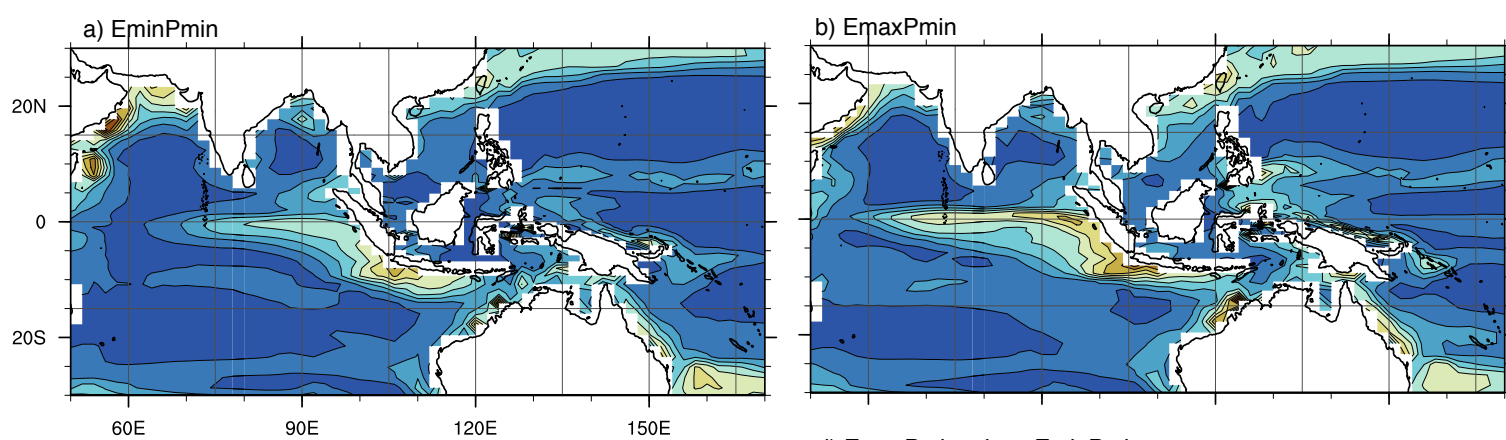

$20 \mathrm{~N}$
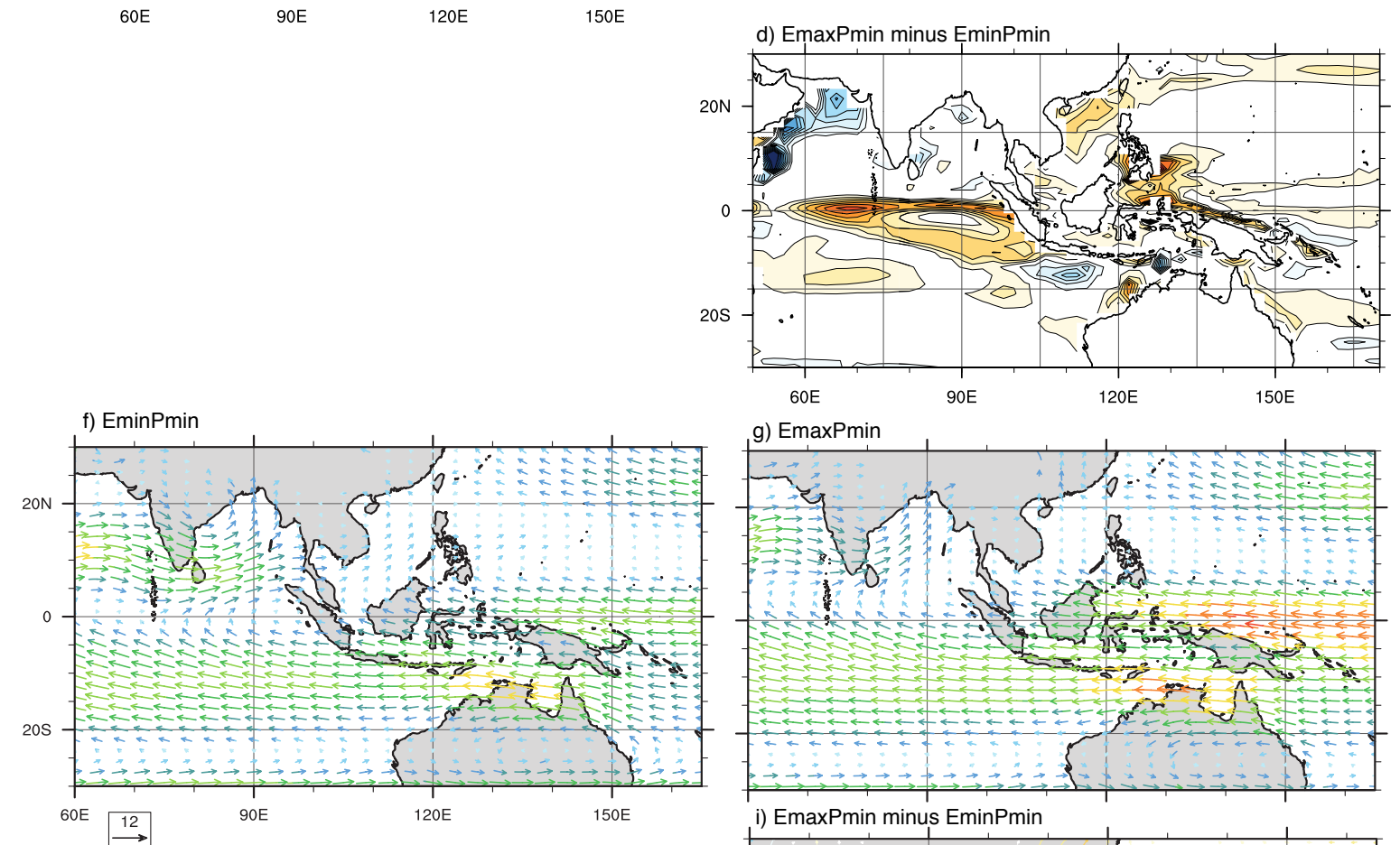

EmaxPmin minus EminPmin (h) EmaxPmax minus EminPmax.
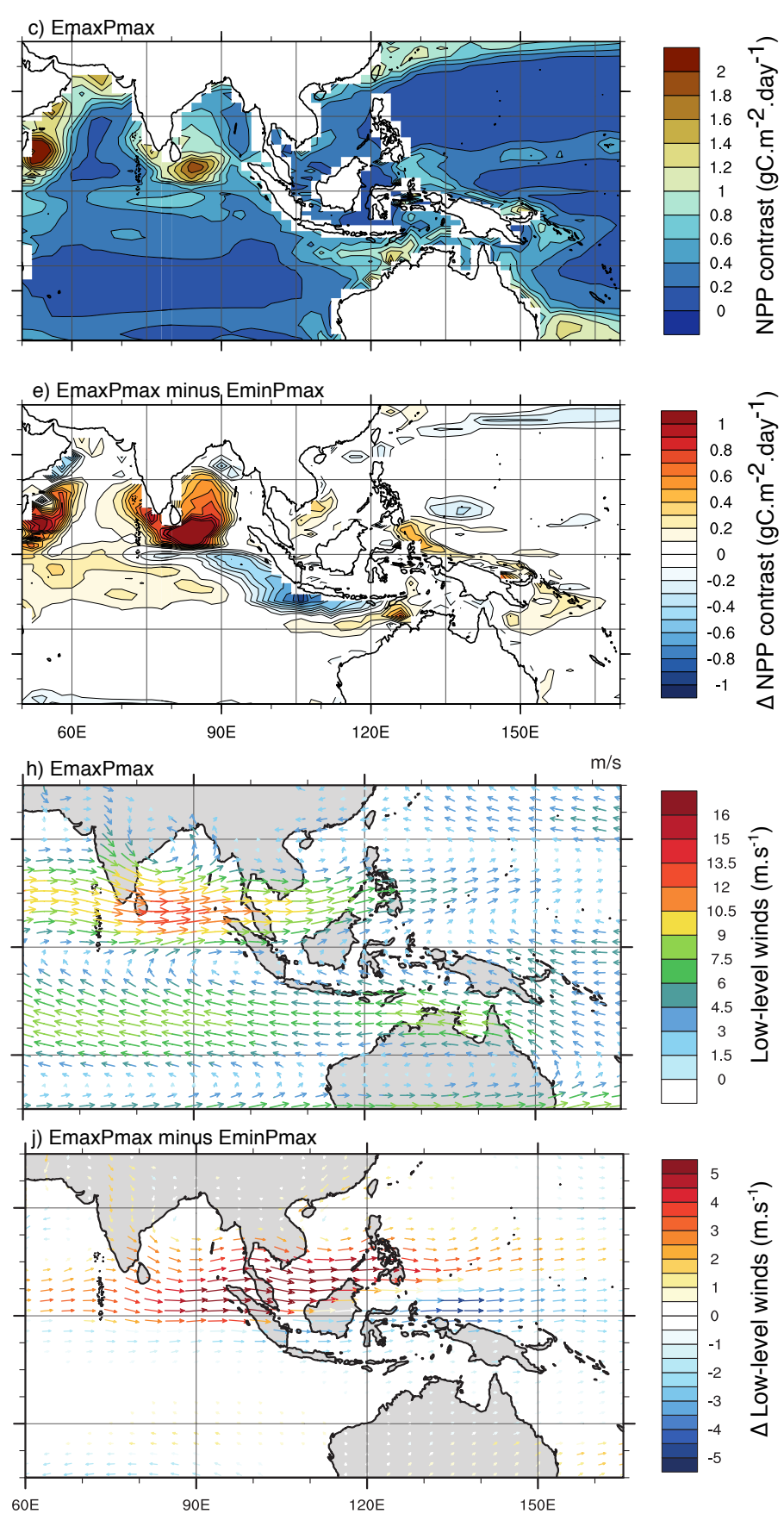

Extended Data Figure 6: Seasonal latitudinal variations of solar radiation at the top of the atmosphere derived from the model (W. $\left.\mathrm{m}^{2}\right)$. (a)

EminPmin, (b) EmaxPmin, (c) EmaxPmax. See Extended Data Table 2 for details of orbital configurations of each simulation. Late summer

(JASO) low-level winds for (d) EminPmin (e) EmaxPmin (f) EmaxPmax simulations and anomaly in late summer low-level winds (g) 

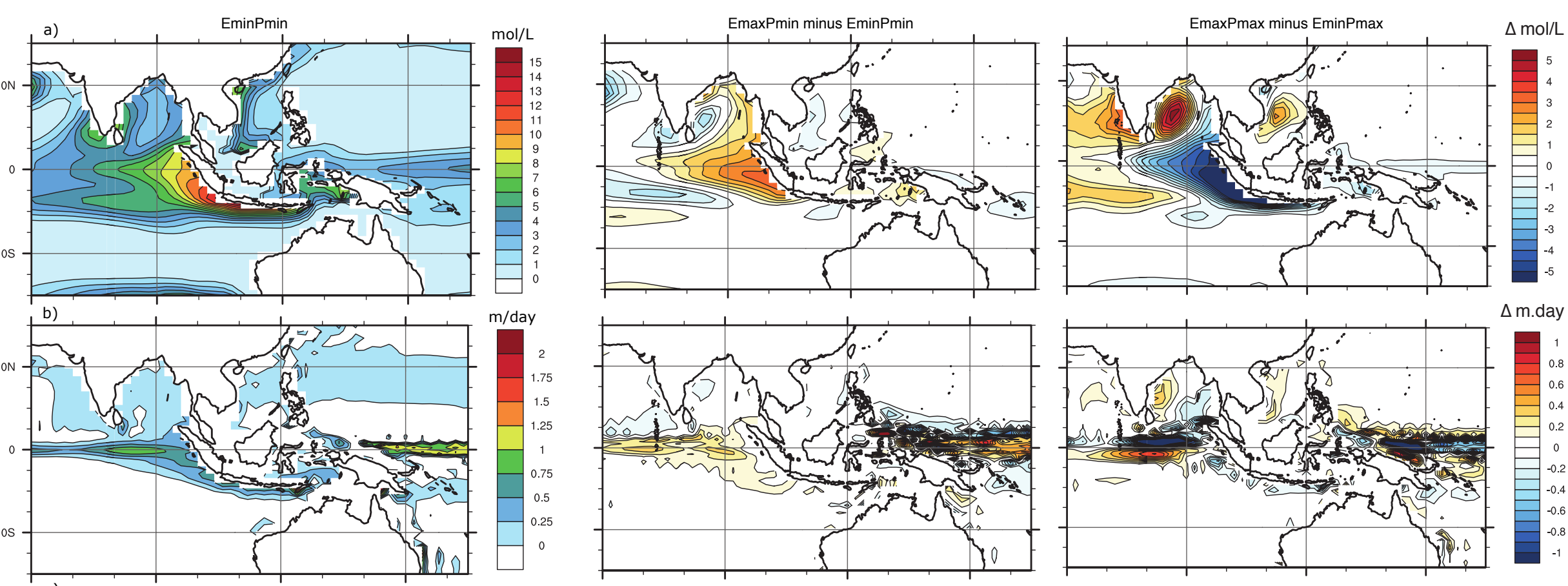

$\Delta$ m.day
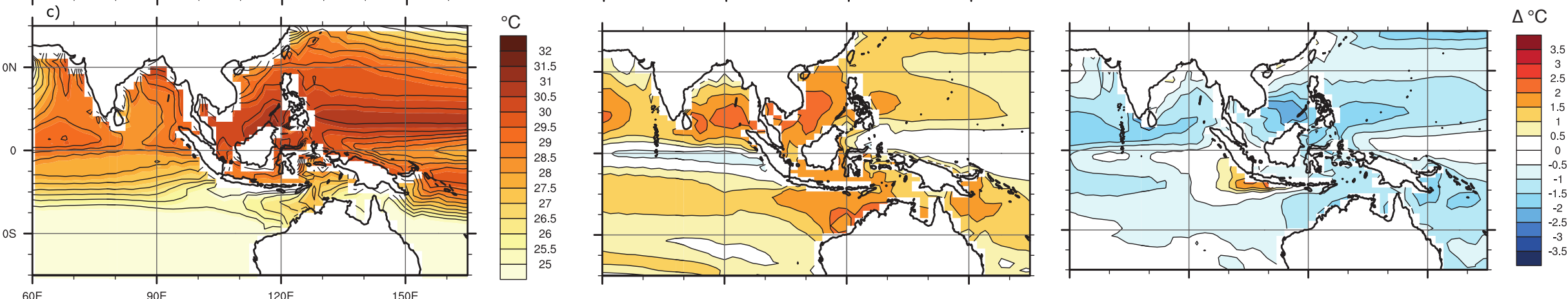

Extended Data Figure 7: (a) $\mathrm{NO}_{3}$ concentrations in the surface layer (0-100m), (b) upwelling velocity (averaged between 40 and $80 \mathrm{~m}$ ), (c) SST.

All variables are averaged over JASO. Left : Emin, Middle : EmaxPmin minus EminPmin, Right : EmaxPmax minus EminPmax.
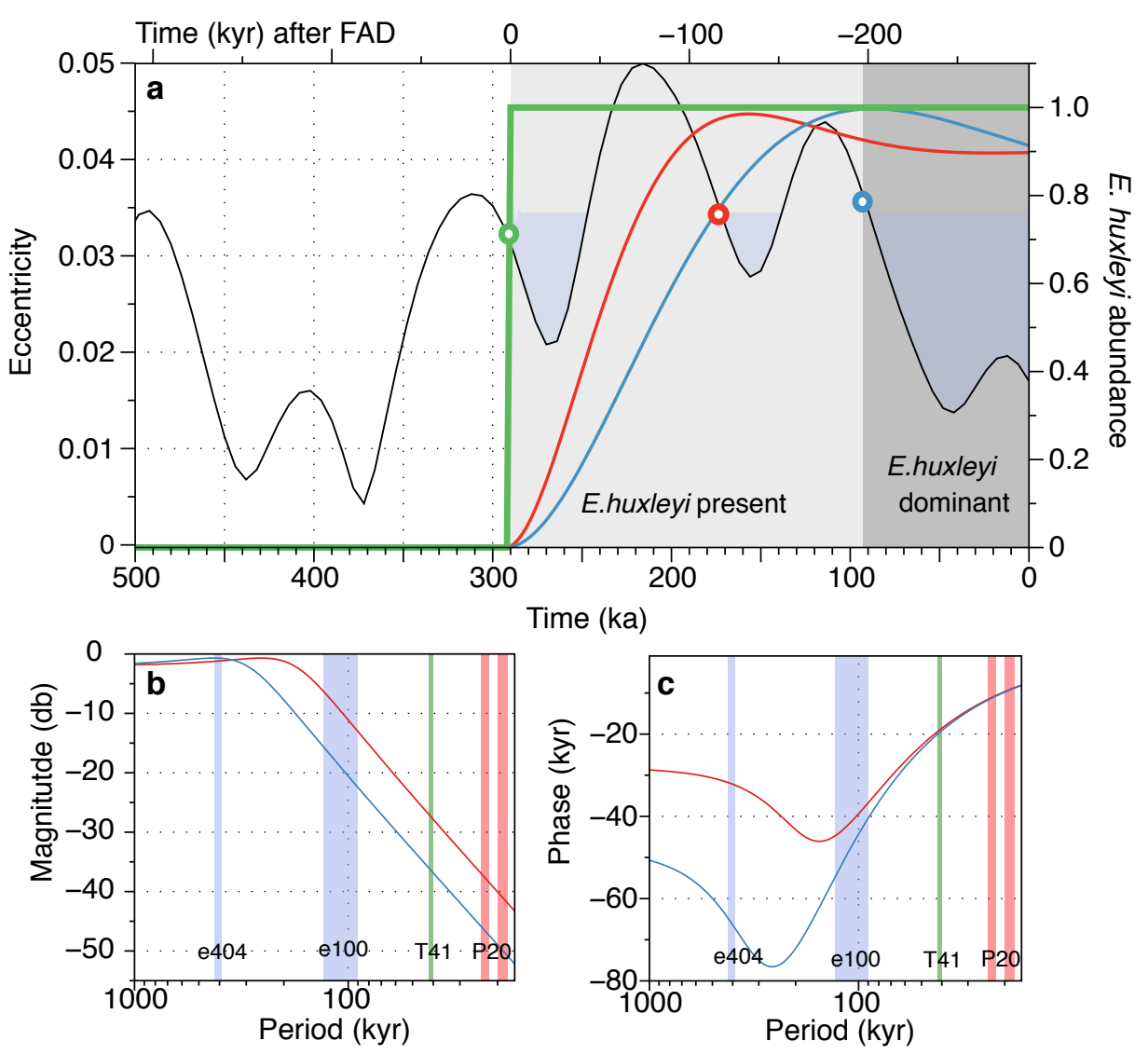
represents E. huxleyi's existence (filtered such that 0 means absence and 1 presence). The blue and red curves are the output series of the 2 lowpass filters described in the methods. The black curve represents coeval eccentricity values. 
555 All morphological data are available at www.microautomate.cerege.fr/data/evolseason.

556 LMDZ, XIOS, NEMO and ORCHIDEE are released under the terms of the CeCILL license. OASIS-MCT is released under the terms of the

557 Lesser GNU General Public License (LGPL). IPSL-CM5A2 source code is publicly available through svn, with the following commands line:

558 svn co http://forge.ipsl.jussieu.fr/igcmg/svn/modipsl/branches/publications/IPSLCM5A2.1_11192019 modipsl ; cd modipsl/util ; ./model

559 IPSLCM5A2.1

560 The mod.def file provides information regarding the different revisions used, namely:

561 - NEMOGCM branch nemo_v3_6_STABLE revision 6665

562 - XIOS2 branchs/xios-2.5 revision 1763

563 - IOIPSL/src svn tags/v2_2_2

564 - LMDZ5 branches/IPSLCM5A2.1 rev 3591

565 - branches/publications/ORCHIDEE_IPSLCM5A2.1.r5307 rev 6336

566 - OASIS3-MCT 2.0_branch (rev 4775 IPSL server)

567 The login/password combination requested at first use to download the ORCHIDEE component is anonymous/anonymous. We recommend that 568 you refer to the project website: http://forge.ipsl.jussieu.fr/igcmg_doc/wiki/Doc/Config/IPSLCM5A2 for a proper installation and compilation of 569 the environment. 


\section{Figures}

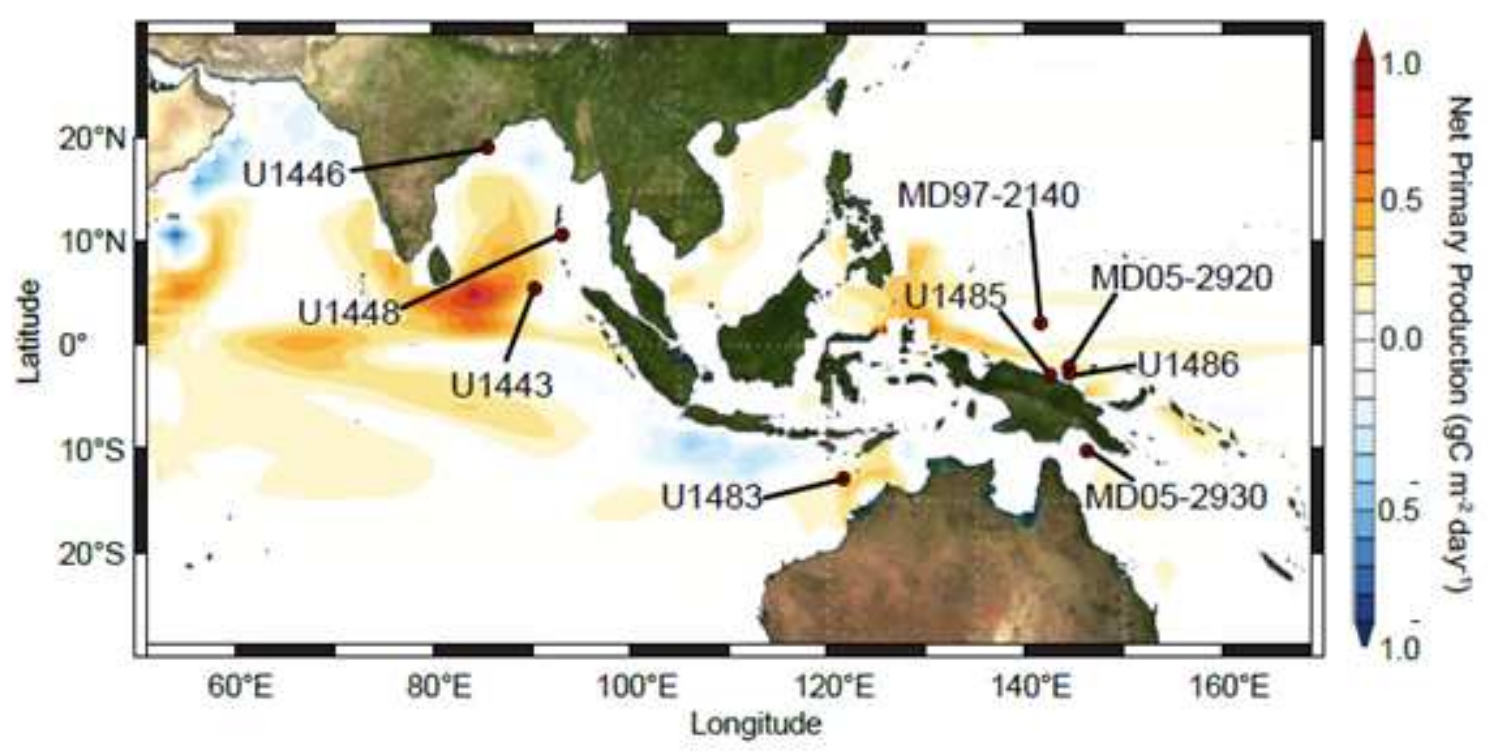

\section{Figure 1}

Core site locations and eccentricity-driven changes in seasonality of primary production in the tropical Indo-Pacific. Colour scale shows the vertically integrated net primary productivity difference between numerical model outputs computed at maximum and minimum eccentricity, each run at perihelion in June (Pmin) and December (Pmax) and then averaged (see Methods). Red (blue) colours imply higher (lower) seasonality at high eccentricity compared to low eccentricity. Note: The designations employed and the presentation of the material on this map do not imply the expression of any opinion whatsoever on the part of Research Square concerning the legal status of any country, territory, city or area or of its authorities, or concerning the delimitation of its frontiers or boundaries. This map has been provided by the authors. 


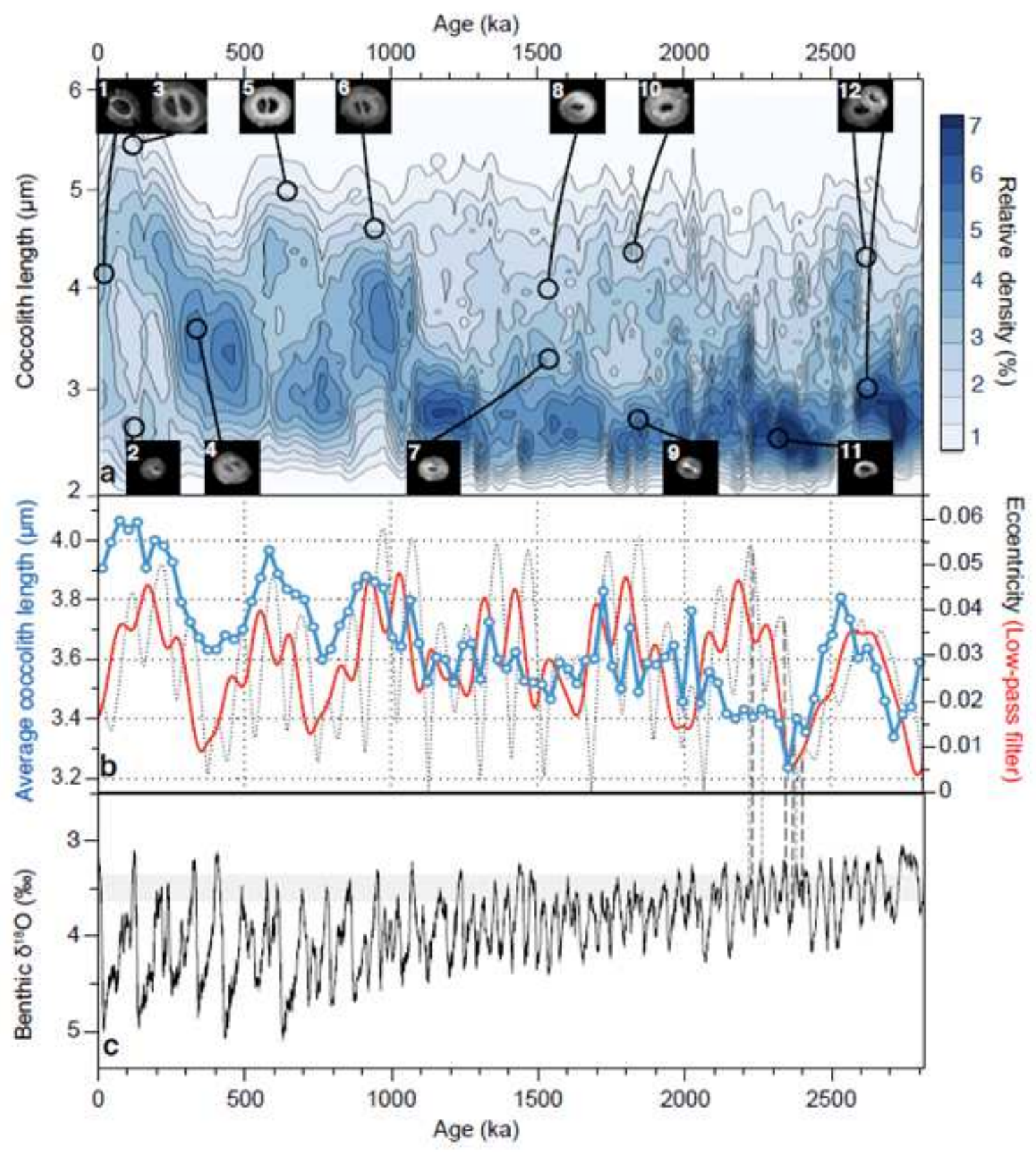

Figure 2

Coccolith size variability over the last 2.8 million years. a: Evolutionary histogram of coccolith length. Samples in each core were grouped into $30 \mathrm{kyr}$ bins, standardised (\%) and merged into a single stack (see Methods). Length bins are $0.1 \mu \mathrm{m}$. Scanning electron microscope images represent typical Noëlaerhabdaceae morphologies. 1: Emiliania huxleyi, 2: Gephyrocapsa ericsonii, 3: Gephyrocapsa oceanica, 4: Gephyrocapsa caribbeanica, 5-6: Gephyrocapsa omega, 7-8: mid-size Gephyrocapsa, 9: small Gephyrocapsa, 10: Pseudoemiliania ovata, 11: Reticulofenestra minuta, 12: left: P. ovata, right: Reticulofenestra minutula. b: Average length (blue) of coccoliths in the multi-site stack, plotted with Earth's eccentricity 19 (dotted black line) and low-pass filtered eccentricity with an angular frequency of $0.021 \mathrm{kyr}-1$ (red) and average coccolith length detrended (blue). c: LR04 benthic foraminiferal $\delta 180$ 
stack18. Vertical dashed lines between panels $b$ and $c$ show orbital configurations used in model simulations (black long dash = Pmin, grey short dash = Pmax; see Methods). Grey band in c illustrates the small range of benthic $\delta 180$ between simulations.

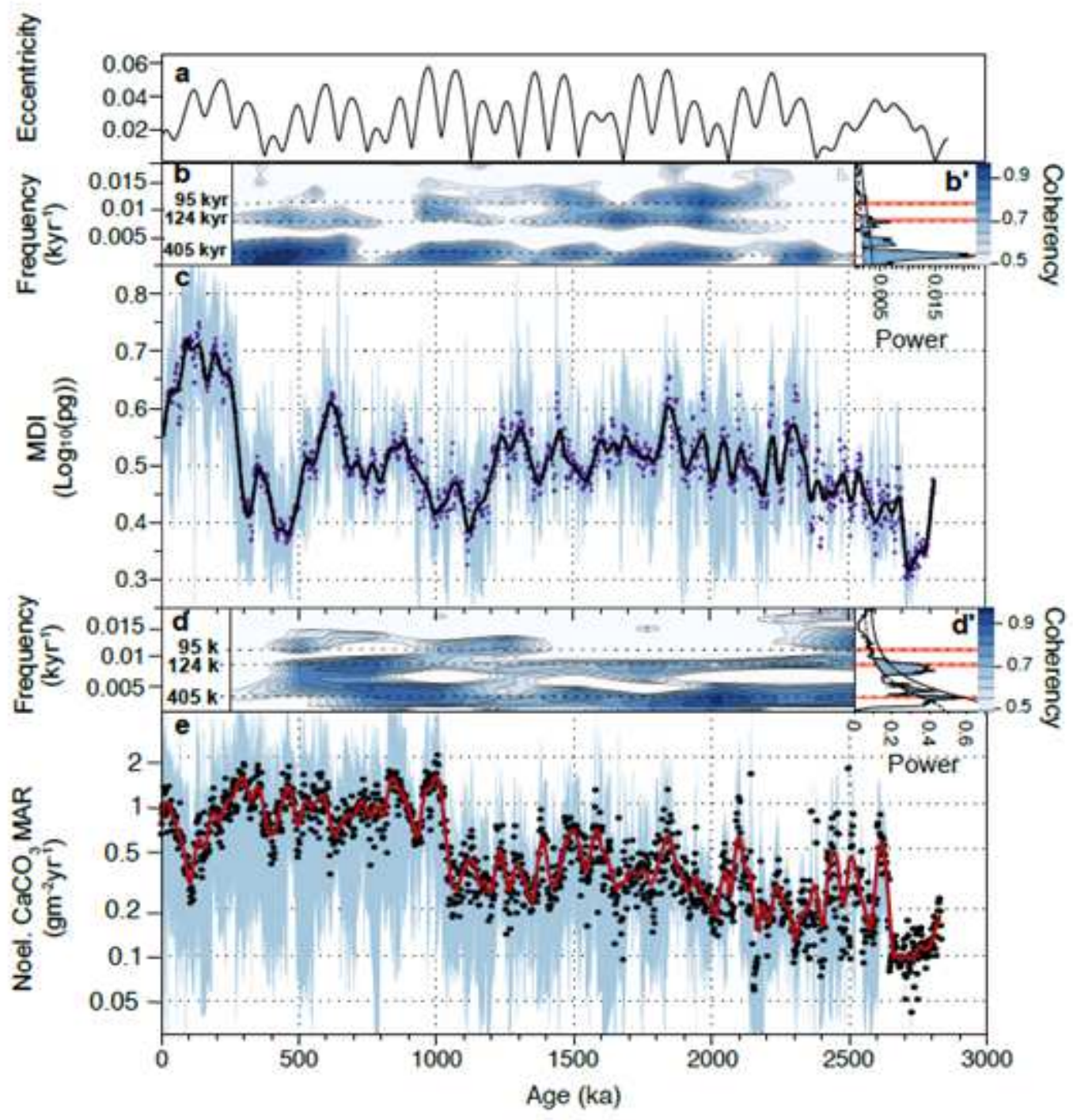

\section{Figure 3}

Eccentricity, coccolith morphological divergence, and Noëlaerhabdaceae $\mathrm{CaCO} 3$ mass accumulation rates. a: Earth's eccentricity 19, b: Evolutive cross-spectral analysis between MDI and eccentricity (see Methods). Colour-scale shows coherency ( $90 \%$ Confidence Level (CL) above 0.7 ); Horizontal dashed lines show eccentricity periods. b': MTM spectral analysis of detrended MDI stack. Shaded areas are above the $90 \% \mathrm{CL}$ (dashed line). Solid black line is $95 \% \mathrm{CL}$. Frequency scale is aligned with b. c: MDI Stack ( $2 \mathrm{kyr}$ resolution, see Methods). Blue shading shows maximum and minimum values from all records. d: Evolutive cross-spectral analysis between MAR and MDI (CLs as in b). d': MTM spectral analysis of detrended MAR stack. CLs as in b'. e: Noëlaerhabdaceae CaCO3 MAR stack (2 kyr resolution, see Methods). Blue shading shows maximum and minimum values from all records. MDI and MAR stacks are smoothed with a LOESS function. 


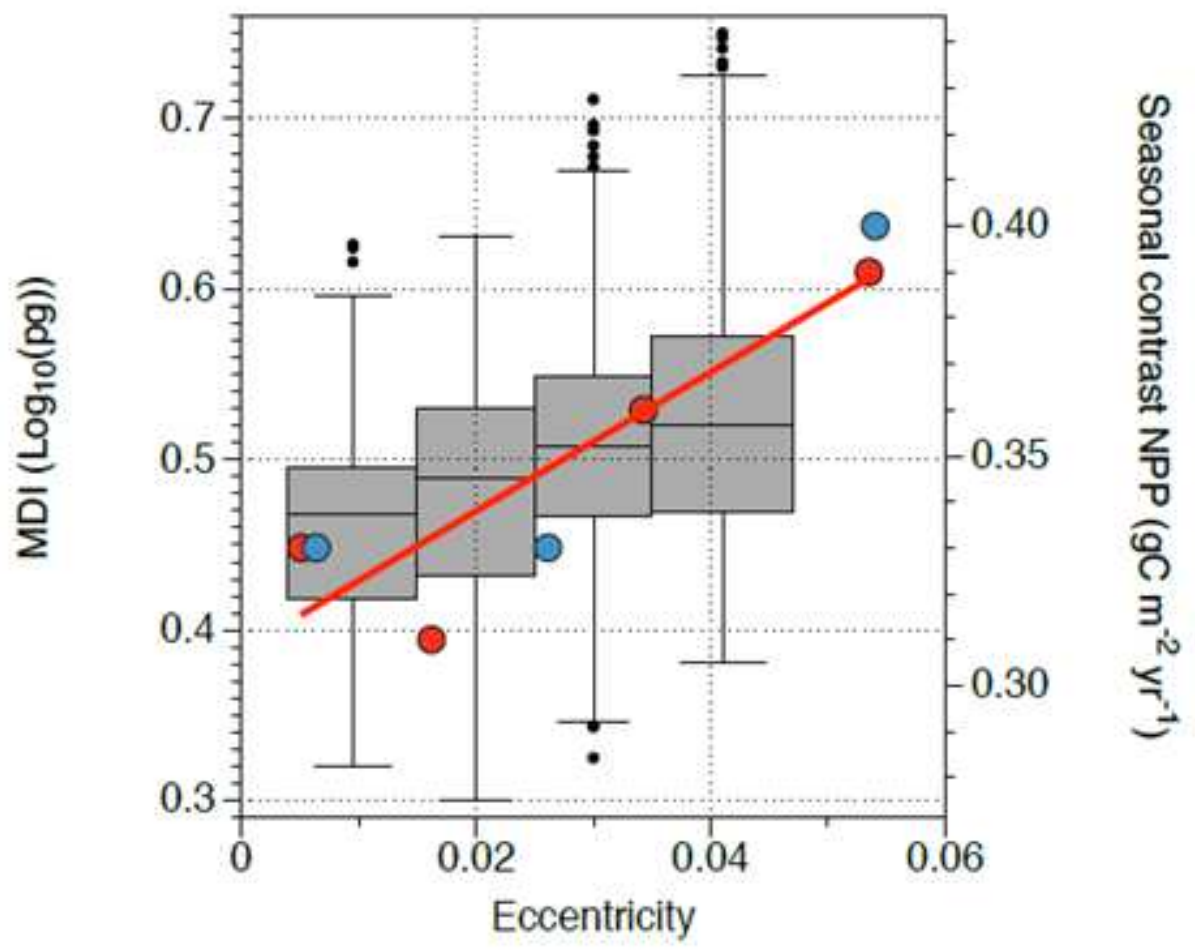

Figure 4

Morphological divergence index and modelled seasonality both increase with eccentricity. Box-whiskers plot of all MDI values, sorted and binned by increasing low-pass filtered eccentricity, compared to the seasonal contrast of net primary production (maximum minus minimum month) from numerical simulations (see Methods). Blue dots are model runs with perihelion in December (Pmax: 2222 ka, 2265 ka, and $2380 \mathrm{ka}$ ), red dots are runs with perihelion in June (Pmin: $2230 \mathrm{ka}, 2346 \mathrm{ka}, 2369 \mathrm{ka}$, and 2395 ka) - illustrating that eccentricity has a much larger effect on seasonality than precession at a given eccentricity. 